Canadian

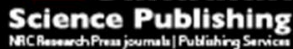

Canadian Geotechnical Journal Revue canadienne de géotechnique

\title{
Analysis of plant root-induced preferential flow and pore water pressure variation by a dual-permeability model
}

\begin{tabular}{|r|l|}
\hline Journal: & Canadian Geotechnical Journal \\
\hline Manuscript ID & cgj-2016-0629.R1 \\
\hline Danuscript Type: & Article \\
\hline Complete List of Authors: & $\begin{array}{l}\text { Shao, Wei; Technische Universiteit Delft; Hong Kong University of Science } \\
\text { and Technology } \\
\text { Ni, Junjun; The Hong Kong University of Science and Technology, } \\
\text { Department of Civil and Environmental Engineering } \\
\text { Leung, Anthony; University of Dundee, Division of Civil Engineering } \\
\text { Su, Ye; charles university in prague } \\
\text { Ng, C.W.W.; Hong Kong University of Science and Technology }\end{array}$ \\
\hline Keyword: & $\begin{array}{l}\text { planting density, suction, preferential flow, dual-permeability model, slope } \\
\text { stability }\end{array}$ \\
\hline &
\end{tabular}




\section{Analysis of plant root-induced preferential flow and pore 2 water pressure variation by a dual-permeability model}

3

$4 \quad$ Wei SHAO ${ }^{1,2}$, Junjun NI ${ }^{1 *}$, Anthony Kwan $\mathrm{LEUNG}^{3}$, Ye $\mathrm{SU}^{4}$, Charles Wang Wai NG ${ }^{1}$

5

6

71 Department of Civil and Environmental Engineering, The Hong Kong University of Science 8 and Technology

92 Water Resources Section, Faculty of Civil Engineering and Geosciences, Delft University 10 of Technology, 2628CN, Delft, Netherlands

113 School of Science and Engineering, University of Dundee, UK

124 Department of Physical Geography and Geoecology, Faculty of Science, Charles University 13 in Prague, 12843, Prague, Czech Republic

$14 \quad{ }^{*}$ Corresponding author (Email: jniaa@ust.hk) 


\begin{abstract}
Vegetation can affect slope hydrology and stability via plant transpiration and its induced matric suction. Previous work suggested that the presence of plant roots would induce preferential flow, and its effects may be more significant when the planting density is high. However, there is a lack of numerical study on how planting density affects soil pore water pressure and shear strength during heavy rainfall. This study aims to investigate the impact of plant root-induced preferential flow on hydro-mechanical processes of vegetated soils under different planting densities. Two modelling approaches, namely single- and dual-permeability models, were integrated with an infinite slope stability approach to simulate pore water pressure dynamics and slope stability. Laboratory tests on soils with two different planting densities for a plant species, Schefflera heptaphylla, were conducted for numerical simulations. The single-permeability model overestimated the pore water pressure in shallow soil and underestimated the infiltration depth. The dual-permeability model, which is able to model the effects of preferential flow, can better capture the observations of rapid increase of pore water pressure and deeper pressure response in the vegetated soil. However, caution should be taken on the choice of pore water pressure when using the dual-permeability model to assess the factor of safety. The dual-permeability model using the pore water pressure in the preferential flow domain and that in the matrix domain would result in lower and higher factor of safety, respectively.
\end{abstract}

Keywords: planting density; suction; preferential flow; dual-permeability model; slope stability 


\section{Introduction}

Vegetation has been recognised as an environmentally friendly restoration technique for slope stabilization. On one hand, due to the mechanical reinforcement of plant root system, the tensile strength provided by roots at the potential slip surface of a slope increases soil shear strength, which may be used to stabilize the landslide-prone areas (Cohen et al. 2009). On the other hand, plant transpiration and root water uptake can induce soil matric suction (equal to negative pore water pressure in unsaturated soils), resulting in an increase in soil shear strength (Ng and Menzies 2007) and a decrease in soil hydraulic conductivity (Leung et al. 2016; Ng and Leung 2012).

Slope restoration is affected by growing and decaying of roots, which would consequently cause changes in both soil hydraulic and mechanical properties (Lehmann and Or 2012). Due to plant life cycle and competition among plants, growing and decaying of roots may lead to changes in tensile strength for the root reinforcement (Cohen et al. 2009). Besides, root occupation and biodegradation has been shown to significantly affect the soil hydraulic properties such as soil water retention curve and saturated hydraulic conductivity (Li and Ghodrati 1994; Scholl et al. 2014; Leung et al. 2015a, b; Vergani and Graf 2015; Ng et al. 2016a). The pattern of infiltration and associated soil moisture and pore water pressure dynamics would therefore be affected by root physiological processes (Snyder et al. 2003).

Planting density is an important factor influencing the physiological processes of roots in terms of growing and decaying, and therefore altering the effectiveness of slope restoration. Low planting density leads to low root biomass production, resulting in a reduction of root reinforcement and root water uptake ( $\mathrm{Ng}$ et al. 2016b). In contrast, high planting density induces higher transpiration during an intermittent period between rainfall events, causing a greater increase in matric suction in root zone. In addition, high planting density may lead to the competition for water, nutrients, and light among neighbouring plants, which could consequently hamper root biomass production, resulting in root decaying (Azam - Ali et al. 1984; Darawsheh et al. 2009; Benomar et al. 2012; Ng et al. 2016b).

Recent studies reported by $\mathrm{Ng}$ et al. $(2016 \mathrm{a}, \mathrm{b})$ found that the growth of plants was accompanied with root biomass production, affecting the root occupancy of soil pore space. As a result, for the case of low planting density, vegetated soil may have relatively lower soil hydraulic conductivity and higher water retention ability than bare soil (Scanlan and Hinz 
2010; Scholl et al. 2014; Leung et al. 2015b; Ng et al. 2016b). In contrast, for the case of high planting density, the presence of decayed roots would increase the saturated hydraulic conductivity and reduce the water retention ability ( $\mathrm{Ng}$ et al. 2016b).

Decayed root channels can compose a self-organized macropores network, in which the preferential flow may be triggered under high-intensity rainfall or wet soil moisture condition (Sidle et al.2001; Jarivs 2007; Ghestem et al. 2011; Nimmo 2012). The rainfall may infiltrate through the interconnected root channels, resulting in rapid water movement and pore water pressure response in deep soil (Beven and Germann 2013). Even in an individual macropore, which is not directly connected to surface infiltration or ponded water, the hydraulic connection can be achieved by pressure propagation and water exchange between macropores and matrix (Nimmo 2007; Nieber and Sidle 2010). Preferential flow can affect tracer transport in terms of reducing travel time, increasing infiltration depth, and affecting concentrations in drainage flow (Jarvis 2007; Beven and Germann 2013). Particularly, under heavy rainfall or snow-melting conditions, the occurrence of preferential flow in a potentially unstable slope could cause rapid infiltration and percolation (Uchida 2004; Shao et al. 2015). Consequently, preferential flow induces fast pore water pressure change at the potential slip surface, and this could play an important role in triggering slope failure (Van Asch et al. 1999; Hencher 2010; Sidle and Bogaard 2016).

The commonly-used numerical models for coupling seepage and slope stability analysis are single-permeability models, which employ the Darcy-Richards equation or its various simplifications (e.g., the linear diffusion equation, Boussinesq equations) in an assumed single-continuum soil(Iverson 2000; Talebi et al. 2008; Lu et al. 2012). A single-permeability model often neglects the effects of preferential flow, so it could underestimate the amount of infiltration, percolation, and drainage in slopes during heavy rainfall (Beven and Germann 2013). Existing numerical studies indicate that the single-permeability model is unable to correctly simulate rapid water and tracer movement in macropore soils (Jarvis 2007; Köhne et al. 2009). Recent studies also suggested that even though the equivalent parameter sets were used by the single-permeability model, it is still not possible to simulate fast pressure response and the associated effects on slope stability (Shao et al. 2015, 2016).

It is a remaining challenge on how to deterministically quantify the impact of preferential flow on slope hydrology and stability (Uchida 2004; Hencher 2010; Bogaard and Greco 2016). Many preferential flow models have been developed such as a pore-network model, dual- or 
102

103

104

105

106

107

108

109

110

111

112

113

114

115

116

117

118

119

120

121

122

123

124

125

126

127

128

129

130

131

132

multi-continuum conceptualization of soil porous media (see review by Köhne et al. (2009)). Specifically, the dual-permeability model uses two coupled Darcy-Richard equations (Gerke and Köhne 2004; Köhne et al. 2009) to quantify the dual-effect of the matrix and preferential flow on infiltration, pressure propagation, and their effects on slope stability (Shao et al. 2015, 2016). Application of such dual-permeability model for an ecological system may be necessary to simulate the hydrological and mechanical responses of soils with widespread decayed roots that potentially form a macropore network.

This study aims to quantify the impact of planting density on soil hydrology, including the response in pressure propagation and their effects on soil mechanical responses and slope stability. Numerical modelling and analyses were conducted to simulate and back-analyse the recent experiments reported by $\mathrm{Ng}$ et al. (2016b). In the experiments, a tree species, Schefflera heptaphylla, with ornamental and ecological value for slope rehabilitation and reforestation was tested. The species were planted in big drums with different planting densities. Root area index was measured to quantify the effects of planting density on root growth and decay. The measured variation of soil pore water pressure during a rainfall event was simulated using both the single- and dual-permeability models. Subsequently, the role of planting density on slope stability was analysed.

\section{Laboratory test}

\section{Test plan, test setup and instrumentation}

Two different planting densities of 36 (test D36), and 320 (test D320) seedlings $/ \mathrm{m}^{2}$, corresponding to the plant spacing of $0.18 \mathrm{~m}$ and $0.06 \mathrm{~m}$ were investigated ( $\mathrm{Ng}$ et al. $2016 \mathrm{~b}$ ). Each planting density was tested with three replicates. There were six drums in total for testing vegetated soils, each of which has a diameter of $0.6 \mathrm{~m}$ and a height of $0.5 \mathrm{~m}$. An additional drum was compacted with bare soil for measuring soil water retention curve and saturated hydraulic conductivity. Multiple-holes were made in the bottom of each drum for creating a free drainage boundary. The targeted plant species, Schefflera heptaphylla, is smallsized, and semi-deciduous. Plant individuals were transplanted to the test drums with a uniform spacing at the targeted plant densities (Figure 1). All the tree individuals, before transplantation, were grown in a nursery under identical growth conditions. The growing media was silty sand (according to the Unified Soil Classification System (USCS; ASTM 2010)), which has the same soil type used in the test drums. These tree individuals have 
133 similar characteristics, including basal diameter of tree stem $(6 \pm 2 \mathrm{~mm})$, tree height $(440 \pm$ $13427 \mathrm{~mm})$, maximum lateral root spread $(60 \pm 15 \mathrm{~mm})$ and root depth $(80 \pm 16 \mathrm{~mm})$. After transplanting to each test drum, all tree individuals were allowed to grow for four months, with regular irrigation to maintain the soil moisture content similar to the field capacity. The choice of growing period of four months was based on previous studies which reported that the survival rates were above $90 \%$ for all species (Kitao et al. 2006) after three months of transplantation. During the growing period of four months, the tree characteristics (i.e., LAI, RAI) all increased significantly ( $\mathrm{Ng}$ et al. 2016b).

The tested soil was completely decomposed granite (CDG) that can be classified as silty sand according to the Unified Soil Classification System (USCS; ASTM, 2010). The CDG was compacted at a dry density of $1780 \mathrm{~kg} / \mathrm{m}^{3}$ for all the test drums. Two vertical arrays of miniature-tip tensiometers were installed at the depth of $0.05,0.10,0.15,0.25$, and $0.35 \mathrm{~m}$ to measure the negative pore water pressure. An array of tensiometers (denoted by R) was located in the middle of the drum that is beneath a tree individual. Another array (denoted by M) was installed next to the array $\mathrm{R}$ with a distance of half-spacing. The volumetric water content at depth of $0.05 \mathrm{~m}$ and $0.10 \mathrm{~m}$ was measured by two soil moisture probes (SM300, Delta-T Device Ltd).

All test drums were placed in a plant room with well-controlled environmental condition. The air temperature and relative humidity were maintained at $25 \pm 1{ }^{\circ} \mathrm{C}$ and $60 \pm 5 \%$, respectively. The radiation energy was provided by the cool white fluorescent lamp with irradiance of 5.0 $\mathrm{MJ} / \mathrm{m}^{2} /$ day, and the wave band was within the range of $400-700 \mathrm{~nm}$ to promote the plant growth ( $\mathrm{Ng}$ et al. 2014). Irrigations were applied frequently to maintain the average soil moisture that was close to the field capacity, which is commonly considered to be sufficient for root growth (Wang et al. 2007).

\section{Test procedures}

A two-stage test was conducted after a 4-month growing period. The first stage was to saturate the drums with a constant ponding head until the soil in each drum was fullysaturated. Afterward, the ponding water was removed and all the drums were exposed to a 4day drying period under the same atmospheric condition. The second stage was commenced immediately after the drying test. Artificial rainfall was applied with a controlled intensity of $73 \mathrm{~mm} / \mathrm{h}$ and duration of $2 \mathrm{~h}$, corresponding to a 10-year return period in Hong Kong (Lam 
164

165

166

167

168

169

170

171

172

173

174

175

176

177

178

179

180

181

182

183

184

185

186

187

188

189

190

191

192

193

194

and Leung 1995). All the drums were inclined at a small angle of $2^{\circ}$ to ensure that any water ponded on the soil surface during rainfall could turn into infiltration-excess overland flow. The distributions of pore water pressure in all drums were recorded at a 10-min interval during the second stage infiltration tests.

After the infiltration test was completed, all plants were carefully removed from each drum. The roots were cleaned to investigate the geometry of root system. For detailed procedures, refer to $\mathrm{Ng}$ et al. (2016b). The rooting depth is defined as the deepest soil depth, beyond which no root can be found. Root area index (RAI) is defined as the ratio of the total root surface area to the cross-section area of soil for a given depth. The ImageJ software was used to reconstruct the root system with high-resolution images (i.e., 12 pixels per unit $\mathrm{mm}$ of length). The root surface area of each cross-section was calculated by converting the pixel number into surface area of roots in $\mathrm{mm}^{2}$.

The measured RAI distribution with soil depth and typical root systems obtained at different planting densities are shown in Figure 2. All the root systems were in parabolic shape along depth. The root system from the test D36 was more dispersed. The average rooting depth in test D36 was $0.16 \mathrm{~m}$, which was 30\% longer than that in test D320 (i.e., $0.125 \mathrm{~m}$ ). However, the largest RAI values of test D320 (i.e., 0.7) was 40\% larger than test D36 (i.e., 0.5). Interestingly, in all the repeated tests, the decayed roots were commonly found in soil of test D320, while the roots in test D36 were mainly fresh and less decayed roots were observed. For the high planting density, more decayed roots are expected because of the intense competition among neighboring plants (Goldberg and Miller 1990).

\section{Mathematical models}

The models described herein aim to capture and simulate the transient infiltration processes and pore water pressure dynamics in a one-dimensional (1D) profile of vegetated soil. For modelling simplicity, the roots in each tested drum are considered to be homogeneously distributed within the root zone. As it has been shown by $\mathrm{Ng}$ et al. (2016b) that any plant transpiration during the short $2 \mathrm{~h}$ rainfall event in the drum tests was minimal, it is reasonable to ignore the plant transpiration as well as soil evaporation in the calculation (Sidle et al.1985; Snyder et al.2003). In this study, the effects of roots on infiltration are represented by the parameterisation of the soil hydraulic parameters, including soil water retention curve and saturated hydraulic conductivity (Leung et al. 2015a, b; Ng et al. 2014, 2016a, b). 


\section{Single-permeability model}

The single-permeability model uses one Darcy-Richards equation to simulate the transient response of pore water pressure to rain-pulses:

$$
C \frac{\partial h}{\partial t}=\frac{\partial}{\partial z}\left[K\left(\frac{\partial h}{\partial z}+1\right)\right]-\Gamma
$$

where $t(\mathrm{~T})$ is time, $C(d \theta / d h)\left(\mathrm{L}^{-1}\right)$ is the differential water capacity, $h(\mathrm{~L})$ is the pressure head, $K\left(\mathrm{LT}^{-1}\right)$ is the unsaturated hydraulic conductivity, and $\Gamma\left(\mathrm{T}^{-1}\right)$ is the source or sink term that may be used to calculate root water uptake (Feddes 1976; Leung et al. 2015a, b) and soil evaporation (if a longer term of soil moisture dry-down and pressure recession was to be modelled). In this study, the term $\Gamma$ is set to be zero, considering that the plant transpiration during the short period of rainfall (2 h) is negligible (Snyder et al. 2003).

The Mualem-van Genuchten model is used to describe the hydraulic properties of vegetated soils (Van Genuchten 1980):

$$
\begin{gathered}
\Theta=\frac{\theta-\theta_{r}}{\theta_{s}-\theta_{r}}= \begin{cases}{\left[1+|\alpha h|^{n}\right]^{-m},} & h<0 \\
1 & , h \geq 0\end{cases} \\
C(\Theta)= \begin{cases}m n \alpha\left(\theta_{s}-\theta_{r}\right) \Theta^{1 / m}\left(1-\Theta^{1 / m}\right)^{m}, h<0 \\
S_{s}, & h \geq 0\end{cases} \\
K(\Theta)=K_{s} \Theta^{0.5}\left[1-\left(1-\Theta^{1 / m}\right)^{m}\right]^{2}
\end{gathered}
$$

where $\Theta(-)$ is the effective saturation, $\theta\left(\mathrm{L}^{3} \mathrm{~L}^{-3}\right)$ is the volumetric water content, subscript $r$ and $s$ denote residual and saturated state, $S_{s}\left(\mathrm{~L}^{-1}\right)$ is the specific storage in saturated soil, and $\alpha$ $\left(\mathrm{L}^{-1}\right), n(-)$, and $m(-)$ are the fitting parameters.

The boundary condition of the single-permeability model can be specified as the flux of rainfall intensity or pressure head for ponding condition. The switch between the two boundary conditions is achieved by theories and formula referring to van Dam and Feddes (2000).

\section{Dual-permeability model}


218 The dual-permeability model uses two Darcy-Richards equations to simultaneously simulate 219 the non-equilibrium phenomenon that is caused by the different pore water flow velocities in 220 preferential flow paths and in soil matrix (Gerke and van Genuchten 1993):

$$
\begin{gathered}
C_{f} \frac{\partial h_{f}}{\partial t}=\frac{\partial}{\partial z}\left[K_{f}\left(\frac{\partial h_{f}}{\partial z}+1\right)\right]-\frac{\Gamma_{w}}{w_{f}} \\
C_{m} \frac{\partial h_{m}}{\partial t}=\frac{\partial}{\partial z}\left[K_{m}\left(\frac{\partial h_{m}}{\partial z}+1\right)\right]+\frac{\Gamma_{w}}{w_{m}}
\end{gathered}
$$

223

224

225

226

227

228

229

230

231

232

233

234

235

236

237

238

239

240

241

242

243

where the subscript $f$ indicates the preferential flow domain, the subscript $m$ indicates the matrix domain, $w(-)$ is the volume fraction of the preferential flow domain or the matrix domain, and $\Gamma_{w}\left(\mathrm{~T}^{-1}\right)$ is the water exchange term (Gerke and van Genuchten 1993):

$$
\Gamma_{w}=\alpha_{w} \frac{K_{m}\left(h_{f}\right)+K_{m}\left(h_{m}\right)}{2}\left(h_{f}-h_{m}\right)
$$

where $\alpha_{w}\left(\mathrm{~L}^{-2}\right)$ is the water exchange coefficient.

The soil hydraulic characteristics of both matrix and preferential flow domain are described by the Mualem-van Genuchten model (Van Genuchten 1980). The total effect adopts the Durner's formula (Durner 1994). The volumetric ratio of the preferential flow and matrix flow sums up to one:

$$
w_{f}+w_{m}=1
$$

The total volumetric water content of the soil is the weighted average of volumetric water contents in two domains:

$$
\theta=w_{f} \theta_{f}+w_{m} \theta_{m}
$$

The same holds for the total saturated hydraulic conductivity of the soil:

$$
K_{S}=w_{f} K_{S f}+w_{m} K_{S m}
$$

The boundary conditions of the Darcy-Richards equation could be specified as pressure head, flux, or mixed. The specified infiltration flux $i\left(\mathrm{LT}^{-1}\right)$ on the dual-permeability soil surface can be divided into two constituting domains (Dusek et al. 2008):

$$
i=w_{f} i_{f}+w_{m} i_{m}
$$

where $i_{f}$ and $i_{m}$ are specified boundary fluxes on the surface of matrix domain and preferential flow domain. 
245 According to a widely-used dual-permeability model developed by Jarvis (1991), preferential

246 flow can be triggered only when/if the rainfall intensity is larger than the infiltration capacity

247 of the matrix flow domain. If the rainfall intensity is smaller than the infiltration capacity of

248 the matrix domain, infiltration mainly occurs in the matrix flow domain. When rainfall

249 intensity applied is much larger than the infiltration capacity of the matrix flow domain, the

250 boundary condition of the matrix domain would switch from flux boundary to pressure head

251 boundary. The water ponded on the soil surface would subsequently flow through the

252 preferential flow domain (Shao et al. 2016). In this study, the preferential flow may not to be

253 triggered at the beginning of a rainfall event; consequently, and the infiltration only starts in

254 the matrix domain (Shao et al. 2016), expressing as:

255

$$
R=i=w_{m} i_{m}
$$

256

257

258

259

260

261

262

263

264

265

266

267

268

269

270

If the specified flow at the matrix surface exceeds its infiltration capacity, the boundary condition of the matrix domain would change to a specified pressure head. Hereafter, the infiltration-excess water at that time-step would be reallocated to the surface boundary of the preferential flow domain:

$$
i_{f}=\frac{R-w_{m} i_{m}}{w_{f}}
$$

If the specified flux for the preferential flow domain is larger than its infiltration capacity, the boundary conditions of both domains would switch to a specified pressure head that corresponds to the depth of ponding water on soil surface.

\section{Infinite slope stability calculation}

In order to investigate the effects of planting density on the slope stability, an infinite slope stability calculation is carried out, considering that the slope is vegetated with Schefflera heptaphylla under the two planting densities in the drum tests. The hydrological processes in the infinite slope are assumed to be the same as what the soils experienced in the drum tests. The factor of safety $F_{s}$ is expressed as the ratio of resisting force to gravitationally driving force with three terms (Lu and Godt 2008): 


$$
F_{s}\left(z_{H}\right)=\underbrace{\frac{\tan \phi^{\prime}}{\tan \alpha}}_{\text {friction angle term }}+\underbrace{\frac{c^{\prime}}{G \sin \alpha \cos \alpha}}_{\text {cohesion term }}-\underbrace{\frac{\sigma^{s}}{G} \frac{\tan \phi^{\prime}}{\sin \alpha \cos \alpha}}_{\text {suction stress term }}
$$

272

273

where $z_{H}(\mathrm{~L})$ is the depth below the slope surface considered for slope stability calculation, $c^{\prime}\left(\mathrm{ML}^{-1} \mathrm{~T}^{-2}\right)$ is the effective soil cohesion, $\phi^{\prime}(\mathrm{deg})$ is the friction angle, $\alpha(\mathrm{deg})$ is the slope angle, and $G\left(\mathrm{ML}^{-1} \mathrm{~T}^{-2}\right)$ is weight of soil:

$$
G=\int_{z_{H}}^{H}\left[\gamma_{s}+\gamma_{w} \theta\right] d z
$$

where $\gamma_{s}$ and $\gamma_{w}\left(\mathrm{ML}^{-2} \mathrm{~T}^{-2}\right)$ are the specific weight of dry soil and water.

The suction stress $\sigma^{s}\left(\mathrm{ML}^{-1} \mathrm{~T}^{-2}\right)$ is given as:

$$
\sigma^{s}=\chi p_{w}=\chi \gamma_{w} h
$$

where $p_{w}\left(\mathrm{ML}^{-1} \mathrm{~T}^{-2}\right)$ is the pore water pressure, and $\chi(-)$ is the matrix suction coefficient, which may be approximated by the effective saturation (Lu et al. 2010).

The hydrological results were sequentially coupled with the soil mechanical calculations in the following ways. The unit self-weight of soil was related to the soil moisture distribution (Eq. (15)). The suction stress and shear strength were influenced by pore water pressure and effective saturation. In the dual-permeability model, the pore water pressure head obtained from either preferential flow domain, or matrix domain, or their weighting may be used as an "effective pressure" $\left(p_{\text {eff }}\right)$ for the slope stability analysis. Shao et al. $(2015,2016)$ selected the pressure of the preferential flow model for stability calculation. This method considered that the infiltration and pressure build-up in preferential flow paths reached a given depth of slope failure plane, hence giving a relatively conservative estimation of slope stability. The simulation conducted in the present study investigated the sensitivity of the choice of $p_{\text {eff }}$ to the $F_{s}$ calculation, using (i) pressure from the preferential flow domain $\left(p_{f}\right)$; (ii) pressure from the matrix domain $\left(p_{m}\right)$; and (iii) the arithmetic mean of the pressure between the two domains (i.e., $0.5 *\left(p_{f}+p_{m}\right)$ ). It should be noted that as far as the authors are aware, there is no theoretical model available to determine the exact weighting of pressure between the two 
domains that would affect soil shear strength. The scenario (iii) aims to explore how the combined effects of the two domains would affect the assessment of slope stability.

\section{Model implementation and parameterization}

\section{Numerical models and parameterization strategies}

The mathematical models were numerically solved by an author-developed script under Python 2.7 programming environment (Shao et al. 2016). The Darcy-Richards equation of single- and dual- permeability models was solved by an implicit finite difference method (van Dam and Feddes 2000; Simunek et al. 2005). The Picard iteration technique was used for each time step. For ensuring numerical accuracy and computational efficiency during the computation, the tolerable errors of water content were specified with 0.0001 , and the time step was adapted in a range of $0.02 \sim 5 \mathrm{~min}$.

A uniform computational grid of $0.01 \mathrm{~m}$ was used to discretize the soil of $0.45 \mathrm{~m}$ depth. Both the single- and dual- permeability models were used to simulate the infiltration tests. In both models, the initial pressure head distribution before the infiltration tests was obtained by the interpolation of the measured pore water pressure head right after the 4-day drying period. Rainfall pulse with the intensity of $73 \mathrm{~mm} / \mathrm{h}$ was set as the upper boundary condition, while the boundaries may switch to the pressure head boundary with a ponding depth of $0.1 \mathrm{~mm}$ under such high-intensity rainfall.

The soil hydraulic parameters were manually calibrated for two layers. The first layer was from the soil surface to the rooting depth (i.e., root zone), in which the soil hydraulic properties were affected by the presence of living and decayed roots. Below the root zone where the soil was less affected by vegetation, the soil hydraulic parameters may be specified to be the same as the bare soil. For numerical simulations, the following calibration strategies were sequentially used to parameterize the models: (1) the soil water retention curves were estimated according to the measurements of soil moisture and pore water pressure; (2) the saturated hydraulic conductivities were estimated according to the measured infiltration rate; and (3) for the dual-permeability model, the water exchange coefficients were estimated according to the measured pore water pressure response. The hydraulic parameters for soils in different experiment cases are listed in Table 1.

\section{Water retention curve}


The soil water retention curves (SWRCs) for single- and dual- permeability model were determined according to water content and pore water pressure as shown in Figure 3. The data points of water content and pressure head can be classified into two categories - drying series and wetting series, depending on whether the data was from the first-stage drying period or the second-stage infiltration period. In the bare soil, the difference between drying and wetting curves is indiscernible. On the contrary, more significant hydraulic hysteresis was found in the vegetated soils (regardless of the planting density). For pore water pressure ranged from 0 to $-10 \mathrm{kPa}$, the changes of water content during the wetting process is generally smaller than that during the drying process, probably because of the presence of macropores.

For the single-permeability model, bare soil and vegetated soils (test D320 and D36) have the same values of $\theta_{r}(0.1)$ and $\theta_{s}(0.3)$. Both parameters, $\alpha$ and $n$, controlling the shape of SWRC, were fitted by the nonlinear least-squares algorithms using the sqcurvefit function in Matlab. The fitted SWRC for bare soil and vegetated soils from single-permeability model are shown in Figures $3 \mathrm{a}, \mathrm{b}, \mathrm{d}$, respectively, with all the fitting parameters shown in Table 1. Both the $n$ and $\alpha$ for the case of high planting density (D320) are relatively larger, which tend to behave like a coarser soil.

The composite SWRC determined by the dual-permeability function is shown in Figures $3 \mathrm{c}$, e. The composite SWRC has two groups of parameters to describe the different hydraulic characteristics of the matrix and preferential flow domains. The parameters ( $\theta$ and $w)$ for the volumetric ratio $\left(w\left(\theta_{s}-\theta_{r}\right)\right)$ of the matrix and preferential flow domains were predefined, according to the measured root volume. The $\theta_{s}$ for the preferential flow domain was thus set to be 0.39 considering the occupancy of decayed roots in soil pore space ( $\mathrm{Ng}$ et al. 2016b), while the $\theta_{s}$ for the matrix domain is calculated according to Eq. 9. The volumetric ratio of the preferential flow domain $w_{f}$ commonly ranges from 0.025 to 0.2 . Note that different choices of $w_{f}$ may result in equifinal parameter sets of SWRCs. This means that different parameter sets of the dual-permeability model could result in the same composite SWRC of the total domain for the dual-permeability model (Köhne et al. 2002). In this study, predefined values of $w_{f}$ were set to be 0.1 and 0.2 for the low and high planting density soils, respectively. This means that the volumetric ratio of soil pores, $w_{f}\left(\theta_{s f}-\theta_{r f}\right)$ belonging to the preferential flow domains for the low and high planting density soil is about $3 \%$ and $6 \%$, 
355

356

357

358

359

360

361

362

363

364

365

366

367

368

369

370

371

372

373

374

375

376

377

378

379

380

381

382

383

respectively. A relatively higher value of $w_{f}$ was specified for the high planting density soil for taking into account the effects of decayed roots (Figure 2). The validity of the use of a higher volumetric ratio $w_{f}$ is discussed in the infiltration analysis later (Section 5.1).

For the dual-permeability model, the parameters, $\alpha$ and n, of the two domains are optimized by fitting measured data of soil water content and pore water pressure using the nonlinear least-square curve fitting algorithm (lsqcurvefit function in Matlab). These optimized values may thus represent the equifinal parameters to describe the SWRC for the dual-permeability model as shown in Figs $3 \mathrm{c}$ and e. The parameter $n$ in the preferential flow domain was calibrated to be 1.5 for both D36 and D320 soils according to the shapes of SWRC. On the other hand, $\alpha$ is related to the air entry pressure, and the specified value for D36 and D320 is 6 and $10 \mathrm{~m}^{-1}$, respectively. For the deeper soil layer beyond the root zone, the soil hydraulic properties may not be affected by root growth and decaying, and the parameters of $\alpha$ and $n$ of both the matrix and preferential flow domains thus followed the same parameters of bare soil.

\section{Saturated hydraulic conductivity and water exchange coefficient}

The values of $K_{s}$ were calibrated based on the results obtained from the infiltration test. The calibrated $K_{s}$ of the bare soil is found to be $0.075 \mathrm{~m} /$ day when using the single-permeability model. For the vegetated soils, the calibrated $K_{s}$ for the high planting density soil (D320; $0.175 \mathrm{~m} /$ day) is higher than that for the low planting density soil (D36; $0.06 \mathrm{~m} /$ day). This is consistent with the experimental observation in Figure 2 that the high planting density soil contained more decayed roots. The decayed roots can affect the soil hydraulic behavior via the changes in the shape of SWRC (Figure 3) and also lead to an increase in $K_{s}$ (Table 1 ).

When using the dual-permeability model, the saturated hydraulic conductivity of the preferential flow domain $K_{s f}$ was set to be $4.5 \mathrm{~m} /$ day, which is 300 and 60 times larger than $K_{s m}$ for the case of low and high planting density, respectively. For the soil within the root zone, the values of $K_{s m}(0.018 \mathrm{~m} /$ day in D36, and $0.075 \mathrm{~m} /$ day in D320 soils $)$ are in the same magnitude as those for the bare soil $(0.075 \mathrm{~m} /$ day $)$. The $K_{s m}$ for the low planting density soil $\left(0.018 \mathrm{~m} /\right.$ day in D36) is lower than the $K_{s}(0.075 \mathrm{~m} /$ day $)$ of the bare soil, and this may be related to the occupations of the live roots ( $\mathrm{Ng}$ et al. 2016a). 
384 In the dual-permeability model, the hydraulic interaction between the matrix and preferential 385 flow domains is governed by the water exchange term $\Gamma_{w}$ in Eq. (7). The water exchange rate 386 between these two domains depends on the parameterization of $\alpha_{w}$. For a larger $\alpha_{w}$, an 387 equilibrium of pore water pressure between the matrix and preferential flow domains required would reach more quickly. In this study, moderate values of $\alpha_{w}$ of 25 and $15 \mathrm{~m}^{-2}$ are used for the low and high planting density soils, respectively. The use of a lower $\alpha_{w}$ for the high planting density soil may be related to the coating effects in biopores (Leue et al. 2010). The hydraulic interaction between root channel and soil matrix may be hampered by the nonwetting effects of soil organic matters (Jarvis 2007). Detailed calibration procedures of $\alpha_{w}$ for a given set of infiltration data through different parameterisation strategies are provided in Shao et al. $(2015,2016)$.

\section{Results and Discussion}

\section{Infiltration rate and cumulative infiltration}

The Infiltration rate and cumulative infiltration during the $2 \mathrm{~h}$ rainfall event are shown in Figure 4. The measurement shows that infiltration rate and amount in D320 are higher than those in D36. According to the study reported by $\mathrm{Ng}$ et al. (2016b), this is mainly attributed to two reasons. For the case of high planting density (D320), the intense competition between neighboring plants results in decayed roots (see Figure 2), hence creating preferential channels that facilitate infiltration. On the other hand, the live root biomass in the case of low planting density (D36) might have occupied the soil pore space, reducing the available pore size and infiltration capacity ( $\mathrm{Ng}$ et al. 2016a).

Both the single- and dual- permeability models can simulate the same cumulative infiltration at the end of the rainfall event in both the cases (Figure 4), which is achieved by calibrating the saturated hydraulic conductivities. As expected, the infiltration rate decreases from a high value (close to the rainfall intensity) to a lower value (close to the saturated hydraulic conductivity) during the $2 \mathrm{~h}$ rainfall period, due to the decreased pressure gradient at the soil surface during the infiltration. Correspondingly, the cumulative infiltration is generally approaching to a nearly constant increasing rate.

The single- and dual- permeability models could simulate infiltration rate well for the case of low planting density (D36). On the contrary, much greater differences between two models 
414 can be found when simulating infiltration rate and cumulative infiltration for the case of high 415 planting density (D320). Infiltration rate and cumulative infiltration in high planting density 416 soil is much higher than that in low planting density soil, and this can be modelled using a 417 high value of $w_{f}$ to describe a higher soil moisture storage in preferential flow domain. At $4183000 \mathrm{~s}$, for instance, the difference between the measured and simulated infiltration amount by the dual-permeability model is less than $15 \%$, but such difference is more than $50 \%$ using the single-permeability model (Figure 4b). The dual-permeability model captures the infiltration behavior better for both low and high planting density soils, while the occurrence of preferential water flow may more significantly affect the infiltration rate and cumulative infiltration for the case of high planting density.

\section{Pore water pressure profile after rainfall}

Figure 5 compares the measured and simulated pore water pressure before and after 1 and $2 \mathrm{~h}$ of rainfall, respectively. Assuming that the tensiometers installed in the soil matrix in the drum tests were to capture pore water responses in the matrix domain, the pore water pressure in the matrix domain $p_{m}\left(=\gamma_{w} h_{m}\right)$ simulated by the dual-permeability model is used for comparison. The initial profile of pore water pressure before rainfall is the result of the 4-day drying (i.e., end of the first stage of the drum tests). Compared with the low planting density soil (D36), the pore water pressure in high planting density soil (D320) is significantly lower both within and below the root zone. This is attributed to the greater transpiration and plant root water uptake at high planting density, causing a significant reduction of soil moisture and pore water pressure.

After $1 \mathrm{~h}$ or $2 \mathrm{~h}$ rainfall, the increased pore water pressure in shallower depth is much more significantly than that in deeper depth, regardless of the planting density considered. After the rainfall, the maximum depth of pressure response in D320 can be up to the depth of $0.35 \mathrm{~m}$, whereas that in D36 is shallower than $0.25 \mathrm{~m}$ depth. The observed pore water pressure responses are consistent with the responses of infiltration rates (Figure 4). Higher infiltration rate in D320 leads to a greater increase in pore water pressure, more cumulative infiltration, higher infiltration rate, and hence deeper infiltration depth.

442 Simulated results from the single-permeability model show that, after 1 or $2 \mathrm{~h}$ rainfall, there

443 are clear wetting fronts within which the pore water pressure increases significantly. The pore 444 water pressure below remains unchanged. However, the single-permeability model 
overestimates the pore water pressure within the wetting front, and underestimates the infiltration depth for both cases of D36 and D320. The considerable changes of pore water pressure in deeper depth during the rainfall tests cannot be simulated by the singlepermeability model. On the contrary, the dual-permeability model appears to give a better match with the measurements of the pore water pressure profiles for the entire depth after 1 and $2 \mathrm{~h}$ of rainfall, despite of a slight overestimation of the pressure at $0.15 \mathrm{~m}$ in D320. The deeper pore water pressure response observed in the experiments can be captured by the dualpermeability model, especially for the high planting density soil where preferential flow may be more significant.

\section{Hydrological processes simulated by single-permeability model}

The simulated vertical profiles of soil water content and pore water pressure during the $2 \mathrm{~h}$ infiltration period by the single-permeability model is shown in Figure 6. The simulation results show that by using the single-permeability model, a clear piston-shape wetting front advancement can be identified from soil moisture and pore water pressure profiles in both the low and high-planting density soils.

In low planting density soil (D36), the wetting fronts advance progressively downwards with time. After $25 \mathrm{~min}$ of rainfall infiltration, the wetting front reaches the depth of $0.05 \mathrm{~m}$, and soil at the top $0.02 \mathrm{~m}$ becomes fully saturated. When rainfall continues from 25 to $120 \mathrm{~min}$, the wetting front advances nearly at a constant velocity. The maximum depth of water infiltration after the rainfall is $0.11 \mathrm{~m}$, and only the soil of the top $0.08 \mathrm{~m}$ is fully saturated. There is no build-up of positive pore water pressure head, because the wetting front does not reach the second soil layer (below the root zone) where the hydraulic conductivity is lower.

For the high planting density soil (D320), even though the values of initial soil water content and pressure are lower than those in the low planting density soil, the variation of wetting front with time is similar. The only difference is the velocity of the wetting front advancement. In high planting density soil (D320), due to the higher infiltration rate (Figure 4), the rate of wetting front advancement is relatively faster, extending the saturated zone to a deeper depth of $0.14 \mathrm{~m}$ (compared to the depth of $0.09 \mathrm{~m}$ found in D36 soils). However, the pressure buildup is still insignificant.

\section{Hydrological processes simulated by dual-permeability model}


475 Figure 7 shows the simulated water content and pressure in the matrix and preferential flow 476 domains, and the water exchanges between the two domains for the low planting density soil 477 (D36). Before rainfall, there is no water exchange between domains (Figure 7f), because the initial pressure distributions in the matrix and preferential flow domains are the same. After 2 min rainfall, most of the rainwater infiltrates into the preferential flow domain, as the rainfall intensity surpasses the infiltration capacity of the matrix domain. Consequently, the wetting front in the preferential flow domain propagates with a relatively high velocity, as revealed by the rapid increase of water content and pore water pressure in the deep soil (Figures 7a, d). This implies that the preferential flow dominants the rainwater transport in soil. This phenomenon becomes more significant after 5-min rainfall, indicating by the highest water exchange at the depth of $0.05 \mathrm{~m}$ in Figure $7 \mathrm{f}$.

Pressure build-up in the preferential flow domain starts when the wetting front propagates beyond the rooting depth (at $0.16 \mathrm{~m}$ depth in D36). Below the root zone, the soil is less permeable. After raining for $30 \mathrm{~min}$, the advancement of the wetting front is relatively slower, and the simulated pore water pressure in the preferential flow domain $p_{f}$ shows a steady distribution (close to a hydrostatic distribution) within the root zone. At the end of the rainfall, the final infiltration depth of rainwater reaches $0.3 \mathrm{~m}$.

Figure 8 shows the simulated distributions of soil water content and pore water pressure by using the dual-permeability model for the high planting density soil (D320). The initial soil water content and pore water pressure in this case are significantly lower than that in the case of low planting density (D36), because of higher transpiration rate. At the beginning of infiltration $(\mathrm{t}=2 \mathrm{~min})$, a significant fraction of rainwater infiltrates to the matrix domain (Figures $8 \mathrm{a}, \mathrm{b}$ ), while the water exchange rates along the soil profile are nearly zero. After 2 min of rainfall when infiltration capacity of the matrix domain has reached, rainwater starts to infiltrate into the preferential flow domain. Afterwards, the preferential flow dominates the pressure propagation. The difference in pore water pressure between the two domains results in the water exchange from the preferential flow domain to the matrix domain.

The final infiltration depth after $2 \mathrm{~h}$ rainfall for the case of high planting density (D320) is $0.35 \mathrm{~m}$, which is deeper than that in D36 $(0.3 \mathrm{~m})$. This is because the cumulative infiltration is higher in the high planting density soil (Figure 4). The infiltrated rainwater may transport through the preferential flow path and more predominantly affect the deeper soil pressure response than the case in low planting density. 
507 Overall, the dual-permeability model can capture the pressure response not only within, but 508 also below the root zone. Under the applied heavy rainfall $(73 \mathrm{~mm} / \mathrm{h})$, the wetting front of the 509 preferential flow is deeper than that of the matrix flow, causing a fast and significant pressure 510 build-up for almost the entire soil profile that cannot be captured by the single-permeability 511 model. Interestingly, the soil in the matrix domain between the depths of 0.1 to $0.3 \mathrm{~m}$ remains 512 largely unsaturated - a hydrological process often called bypass flow. Although there are 513 substantial increases of water content and pore water pressure in deeper soil depths, the non514 equilibrium between the matrix and the preferential flow domains are revealed to be different 515 in low and high planting density soils. The simulations using the dual-permeability model 516 show that the preferential flow could lead to more significant responses of water content, and 517 the increase of pore water pressure in the high planting density soil is larger than those in the 518 low planting density soil.

\section{Preferential flow effects on slope stability}

520

521

522

523

524

525

526

527

528

529

530

531

532

533

534

535

The stability of infinite vegetated slopes with a gradient of $28^{\circ}$ is analysed. The mechanical properties of the CDG soils used in the drum tests were reported by Liu et al. (2015). The effective cohesion of the CDG is $0 \mathrm{kPa}$, while the effective friction angle is $37.4^{\circ}$. The effective cohesion contributed by mechanical root reinforcement was set to a relatively low value of $2 \mathrm{kPa}$ and is assumed to be constant and distributed uniformly within the root zone. The values of factor of safety $\left(F_{s}\right)$ of the vegetated slopes with two planting densities (i.e., D36 and D320) were calculated by combining the infinite slope stability modelling approach (Eq. $14-16$ ) with the single- or dual- permeability models.

The calculated profiles of $F_{s}$ before and after $2 \mathrm{~h}$ rainfall are shown in Figure 9. When using the single-permeability model, the simulated pore water pressure (Figures 6b, d) can be used as an input to Eq. 14 for calculating its corresponding $F_{s}$. For the calculation of $F_{s}$ using the dual-permeability model (with $p_{\text {eff }}=p_{f}$ ), the simulated pore water pressure in the preferential flow domain (Figures 7d, 8d) was substituted into Eq. 14 - 16. The pressure build-up and the wetting front advancement by the preferential flow were much more significant than in the matrix flow domain. Therefore, using $p_{f}$ to calculate $F_{s}$ could provide a more conservative assessment of the slope stability. 
536 Before rainfall, the $F_{s}$ calculated by the two models are identical to each other. The $F_{s}$ in the 537 high planting density slope (D320) is much higher than that of the low planting density slope 538 (D36) because of the reduction of pore water pressure by evapotranspiration. After $2 \mathrm{~h}$ of rainfall, the $F_{s}$ calculated by the single-permeability model is larger than 1.0 along the entire soil profile, regardless of the planting density considered. This means that no slope failure exists in both cases. It can be seen that the decrease of $F_{s}$ happened mainly within the wetting front, where the pore water pressure increases significantly (refer to Figure 6). The volume of soil being affected is found to be greater in the slope with high planting density because of the increased infiltration rate (refer to Figure 4). In contrast, $F_{s}$ below the wetting front remains unchanged. As has been revealed from the comparison shown in Figure 5, the use of the single-permeability model may underestimate the pore water pressure in deep soil compared with the measurement, due to its inability to capture preferential flow that might have taken place in the vegetated soils. This highlights the importance of having the preferential flow to be captured when assessing pore water pressure distributions in vegetated soil, in order to prevent overestimation, hence less conservative, on slope stability calculation.

With the assumption of $p_{\text {eff }}=p_{f}$, the calculated $F_{s}$ by the dual-permeability model is lower than that calculated by the single-permeability model. The relatively high $F_{s}$ in very shallow depth is contributed by the mechanical root reinforcement, despite of the low effective cohesion provided by roots of $2 \mathrm{kPa}$. Near and slightly below the interface between rooted and bare soil, the dual-permeability model predicts $F_{s}$ to be lower than 1.0, indicating a potential slope failure. This is attributed to the relatively rapid pore water pressure build-up

557 due to the presence of preferential flow. Such preferential flow appears to exist in both the 558 low and high planting density soils, but it is comparatively more significant for the latter case 559 due to the much higher cumulative infiltration and infiltration rate (Figure 2 and 4). The more 560 decayed roots in the high planting density soil would result in more infiltration and larger value of pressure build-up, which adversely affects the slope stability. However, it should be noted that setting $p_{\text {eff }}$ to be $p_{f}$ represents a worst-case scenario that may lead to a rather conservative calculation of factor of safety. 
565

566

567

568

569

570

571

572

573

574

575

576

577

578

579

580

581

582

583

584

585

586

587

588

589

590

591

592

593

594

In a heterogeneous soil where preferential flow could happen, it remains unknown about the relative contribution of pore water pressure between the matrix domain and preferential flow domains to the soil shear strength. Most of the existing hydro-mechanical models use singlepermeability model to calculate pore water pressure in soil matrix for slope stability analysis. When coupling a dual-permeability model (which adopts a dual-continuum approach) with a slope stability model, using the pore water pressure of $p_{f}$ or $p_{m}$ may lead to different results in slope stability calculations. Instead of using $p_{f}$ as $p_{\text {eff }}$ to calculate $F_{s}$ (as have been shown in Figure 9), it may be necessary to investigate how different choices of $p_{\text {eff }}$ would affect $F_{s}$.

Comparison of $F_{s}$ calculated by using different $p_{\text {eff }}$ (i.e., $p_{f}, p_{m}$, or their arithmetic mean $\left(0.5^{*}\left(p_{f}+p_{m}\right)\right)$ is given in Figure 10. As expected, regardless of the planting density, the calculated profile of $F_{s}$ using $p_{m}$ is much higher than that calculated one using $p_{f}$, because the pore water pressure in the matrix domain is significant higher than that in the preferential domain (see Figures 8d, e and 9d, e). This suggests that it is less conservative for the stability calculation of vegetated soil to use $p_{m}$ to completely ignore the effects of preferential flow.

In an attempt to examine the combined effects of $p_{f}$ and $p_{m}$ on $p_{\text {eff }}$ and slope stability, the calculated $F_{s}$ using the arithmetic mean (i.e., $\left.0.5^{*}\left(p_{f}+p_{m}\right)\right)$ is obtained for both the low and high planting density soils in Figure 10. As expected, the calculated $F_{s}$ in both cases falls between the values obtained by either $p_{f}$ or $p_{m}$, though the $F_{s}$ tends to be closer to the latter case. Note that the above calculation has made an assumption on the equal weighting on the contribution of $p_{f}$ and $p_{m}$ to shear strength. As far as the authors are aware, the exact weighting is not known and it is believed to be dependent on the geometry, location, and distribution of the preferential flow channels and potential failure surface. More detailed investigation to correlate preferential flow with soil shear strength is needed in the future.

The practical application of the dual-permeability model relies on the careful calibration of the hydraulic properties of the two domains. These properties may be identified through insitu testing such as tracer experiments (Krzeminska et al. 2014). This kind of testing allows simultaneous measurements of specific discharge, soil moisture, pore water pressure, and tracer concentration, which can be used to infer water flow paths and residence times for calibrating the dual-permeability model. 


\section{Summary and concluding remarks}

596

597

598

599

600

601

602

603

604

605

606

607

608

609

610

611

612

613

614

615

616

617

618

619

620

621

622

623

624

625

Effects of plant-induced preferential flow on soil hydrology and slope stability were explored through experimental and numerical modelling approaches in this study. Rainfall infiltration tests were conducted in compacted silty sand vegetated plots with a selected tree species, Schefflera heptaphylla, with two different planting densities (i.e., high planting density 320 seedlings $/ \mathrm{m}^{2}$ and low planting density 36 seedlings $/ \mathrm{m}^{2}$ ). In order to capture the effects of root decaying on preferential flow, two numerical models were implemented to simulate the infiltration tests: one is the single-permeability model (which uses one Darcy-Richards equation to consider matrix flow-only), and another is the dual-permeability model (which couples two modified Darcy-Richards equations to simulate both matrix and preferential flow). The calibrated hydrological models were further used to evaluate the effects of plantinduced preferential flow on the stability of infinite vegetated slopes.

The root-induced changes in SWRC were able to be captured by both the single- and dualpermeability models. The dual-permeability model, in which preferential flow could be modelled by the dual-continuum approach, showed a closer match with the measurements than the single-permeability model. The single-permeability model however significantly underestimated the infiltration rate at the beginning of rainfall $(0-20 \mathrm{~min})$ and then overestimated during the last period (80-120 $\mathrm{min})$.

Considering both preferential flow and matrix flow domains when using the dual-permeability model showed that preferential water flow was likely to take place in both low and high planting density. The preferential flow effects appeared to be more significant in the high planting density soil because of the greater increase in pore water pressure and deeper depth of infiltration. These hydrological processes were, however, not possible to be captured by the single-permeability model due to its inability to simulate the preferential flow effect using the matrix flow domain alone. Instead, the single-permeability model simulated the piston-shape of wetting front advancement during rainfall, which resulted in significant under-prediction of infiltration depth and overestimation of the pore water pressure within the root zone.

Because of the inability of the single-permeability model, a less conservative calculation of slope stability is resulted. Regardless of the planting density considered, the singlepermeability model estimated significantly higher factor of safety than the dual-permeability model, especially on the deeper soil depths below the root zone. In contrast, when the dual- 
626 permeability model was used, a lower factor of safety resulted. While the shallow stability of 627 the vegetated slopes (up to $0.1 \mathrm{~m}$ depth within the root zone) is mainly provided by the 628 mechanical root reinforcement, the factor of safety below the root zone is marginally closer to 629 1. Although the dual-permeability model is better to capture the variations of pore water 630 pressure in vegetated soils, caution should be taken on the choice of effective pressure when 631 using this model to assess the factor of safety. Simulation using the pore water pressure in the 632 preferential flow domain and the matrix domain in the model would result in over- and under633 conservative assessment of the stability of vegetated slopes, respectively.

634

\section{Acknowledgements}

Research grants HKUST6/CRF/12R provided by the Research Grants Council of the Government of the Hong Kong SAR is acknowledged. The first author is financially supported by the scholarship (No. 2011671055) provided by the China Scholarship Council. The third author would also like to acknowledge the EU Marie Curie Career Integration Grant under the project 'BioEPIC slope' and research travel support from the Northern Research 641 Partnership (NRP).

\section{References}

ASTM 2010. Standard practice for classification of soils for engineering purposes (Unified 645 Soil Classification System). West Conshohocken, PA, USA: American Society for Testing and Materials.

Azam-Ali, S. N., Gregory, P. J., and Monteith, J. L. 1984. Effects of planting density on water use and productivity of pearl millet (Pennisetum typhoides) grown on stored water: growth of roots and shoots. Experimental Agricultural, 20(3): 203-214.

Benomar, L., DesRochers, A., and Larocque, G. 2012. The effects of spacing on growth, morphology and biomass production and allocation in two hybrid poplar clones growing in the boreal region of Canada. Trees - Structure and Function, 26(3): 939-949. 
655 Bogaard, T. A., and Greco, R. 2016. Landslide hydrology: from hydrology to pore pressure. 656 Wiley Interdisciplinary Reviews: Water 3(3): 439-459.

657 Cohen, D., Lehmann, P., and Or, D. 2009. Fiber bundle model for multiscale modeling of 658 hydromechanical triggering of shallow landslides. Water Resources Research, 45(10): 659 W10436.

660 Darawsheh, M. K., Khah, E. M., Aivalakis, G., Chachalis, D., and Sallaku, F. 2009. Cotton 661 row spacing and plant density cropping systems I. Effects on accumulation and partitioning of 662 dry mass and LAI. Journal of Food Agricultural and Environment, 7(3-4): 258-261.

663 Durner, W. 1994. Hydraulic conductivity estimation for soils with heterogeneous pore 664 structure. Water Resources Research, 30(2): 211-223.

665 Dusek, J., Gerke, H. H., and Vogel, T. 2008. Surface Boundary Conditions in Two666 Dimensional Dual-Permeability Modeling of Tile Drain Bromide Leaching. Vadose Zone 667 Journal, 7(4): 1287-1301.

668 Feddes, R. A., Kowalik, P., Kolinska-Malinka, K., and Zaradny, H. 1976. Simulation of field 669 water uptake by plants using a soil water dependent root extraction function. Journal of 670 Hydrology, 31(1): $13-26$.

671 Gerke, H. H., and Köhne, J. M. 2004. Dual-permeability modeling of preferential bromide 672 leaching from a tile-drained glacial till agricultural field. Journal of Hydrology, 289(1): 239673257.

674 Gerke, H. H., and van Genuchten, M. 1993. Evaluation of a first-order water transfer term for 675 variably saturated dual-porosity flow models. Water Resources Research, 29(4): 1225-1238.

676 Ghestem, M., Sidle, R. C., and Stokes, A. 2011. The influence of plant root systems on 677 subsurface flow: implications for slope stability. Bioscience, 61(11): 869-879.

678 Goldberg, D. E., and Miller, T. E. 1990. Effects of different resource additions on species 679 diversity in an annual plant community. Ecology, 71(1): 213-225.

680 Hencher, S. R. 2010. Preferential flow paths through soil and rock and their association with 681 landslides. Hydrological Processes, 24(12): 1610-1630. 
682 Iverson, R. M. 2000. Landslide triggering by rain infiltration. Water Resources Research, 683 36(7): 1897-1910.

684 Jarvis, N. J. 2007. A review of non-equilibrium water flow and solute transport in soil 685 macropores: principles, controlling factors and consequences for water quality. European 686 Journal of Soil Science, 58(3): 523-546.

687 Jarvis, N. J., Jansson, P.-E., Dik, P. E., and Messing, I. 1991. Modelling water and solute 688 transport in macroporous soil. I. Model description and sensitivity analysis. Journal of Soil 689 Science, 42: 59-70. doi:10.1111/j.1365-2389.1991.tb00091.x

690 Kitao, M., Yoneda, R., Tobita, H., Matsumoto, Y., Maruyama, Y., Arifin, A., Mohamad 691 Azani, A., and Muhamad, M. N. 2006. Susceptibility to photoinhibition in seedlings of six 692 tropical fruit tree species native to Malaysia following transplantation to a degraded land. 693 Tree, 20: 601-610.

694 Köhne, J. M., Köhne, S., and Gerke, H. H. 2002. Estimating the hydraulic functions of dual695 permeability models from bulk soil data, Water Resources Research, 38(7): doi:10.1029/ 696 2001WR000492, 2002.

697 Köhne, J. M., Köhne, S., and Šimůnek, J. 2009. A review of model applications for structured 698 soils: a) Water flow and tracer transport. Journal of Contaminant Hydrology, 104(1-4): 4-35.

699 Krzeminska, D. 2012. The influence of fissures on landslide hydrology, TU Delft, Delft 700 University of Technology.

701 Krzeminska, D. M., Bogaard, T. A., Debieche, T.H., Cervi, F., Marc, V., and Malet, J. P. 702 2014. Field investigation of preferential fissure flow paths with hydrochemical analysis of 703 small-scale sprinkling experiments, Earth Surface Dynamics, 2(1): 2: 181-195.

704 Leue, M., Ellerbrock, R. H., and Gerke, H. H. 2010. DRIFT Mapping of Organic Matter 705 Composition at Intact Soil Aggregate Surfaces. Vadose Zone Journal, 9(2): 317-324.

706 Lehmann, P., and Or, D. 2012. Hydromechanical triggering of landslides: From progressive 707 local failures to mass release. Water Resources Research, 48(3): W03535 
708 Leung, A. K., Coo, J. L., Ng, C. W. W., and Chen, R. 2016. New transient method for 709 determining soil hydraulic conductivity function. Canadian Geotechnical Journal, 53(8): 1332 $710-1345$

711 Leung, A. K., Garg, A., and Ng, C. W. W. 2015a. Effects of plant roots on soil-water 712 retention and induced suction in vegetated soil. Engineering Geology, 193: 183-197.

713 Leung, A. K., Garg, A., Coo, J. L., Ng, C. W. W., and Hau, B. C. H. 2015b. Effects of the 714 roots of Cynodon dactylon and Schefflera heptaphylla on water infiltration rate and soil 715 hydraulic conductivity. Hydrological Processes, 29(15): 3342 - 3354.

716 Li, Y., and Ghodrati, M. 1994. Preferential transport of nitrate through soil columns 717 containing root channels. Soil Science Society of American Journal, 58: 653-659.

718 Liu, H. W., Feng, S., and Ng, C. W. W. 2016. Analytical analysis of hydraulic effect of 719 vegetation on shallow slope stability with different root architectures. Computers and 720 Geotechnics, 80: 115-120.

721 Lu, N., and Godt, J. 2008. Infinite slope stability under steady unsaturated seepage conditions. 722 Water Resources Research, 44(11): W11404.

723 Lu, N., Godt, J. W., and Wu, D. T. 2010. A closed-form equation for effective stress in 724 unsaturated soil. Water Resources Research, 46(5): W05515.

725 Lu, N., Şener-Kaya, B., Wayllace, A., and Godt, J. W. 2012. Analysis of rainfall-induced 726 slope instability using a field of local factor of safety. Water Resources Research, 48(9): 727 W09524.

$728 \mathrm{Ng}$, C. W. W., and Menzies, B. 2007. Advanced unsaturated soil mechanics and engineering. 729 London, UK: Taylor \& Francis.

$730 \mathrm{Ng}$ C. W. W., and Leung A. K. 2012. Measurements of drying and wetting permeability 731 functions using a new stress-controllable soil column. Journal of Geotechnical and 732 Geoenvironmental Engineering, 138(1): 58-68.

$733 \mathrm{Ng}, \mathrm{C} . \mathrm{W}$. W., Leung, A. K., and Woon, K. X. 2014. Effects of soil density on grass-induced 734 suction distributions in compacted soil subjected to rainfall. Canadian Geotechnical Journal, 735 51(3): 311-321. 
736 Ng, C. W. W., Ni, J. J., Leung, A. K., and Wang, Z. J. 2016a. A new and simple water 737 retention model for root-permeated soils. Géotechnique letters, 6(1): $106-111$.

738 Ng, C. W. W., Ni, J. J., Leung, A. K., Zhou, C., and Wang, Z. J. 2016b. Effects of planting 739 density on tree growth and induced soil suction. Géotechnique, 66(9): 711-724.

740 Nieber, J. L., and Sidle, R.C. 2010. How do disconnected macropores in sloping soils 741 facilitate preferential flow? Hydrological Processes, 24(12):1582-1594.

742 Nimmo, J. R. 2007. Simple predictions of maximum transport rate in unsaturated soil and 743 rock. Water Resources Research, 43(5): W05426.

Nimmo, J. R. 2012. Preferential flow occurs in unsaturated conditions. Hydrological 745 Processes, 26(5): 786-789.

746

747

748

749

750

751

752

753

754

755

756

757

758

759

760

761

762

Scanlan, C. A., and Hinz, C. 2010. Insight into the processes and effects of root induced changes to soil hydraulic properties. Proceedings of the 19th world congress of soil science, soil solutions for a changing world, Brisbane, Australia, vol. 2, pp. 41-44.

Scholl, P., Leitner, D., Kammerer, G., Lioskandl, W., Kaul, H. P., and Bodner, G. 2014. Root induced changes of effective 1D hydraulic properties in a soil column. Plant and Soil, 381(12), 193-213.

Shao, W., Bogaard, T., and Bakker, M. 2014. How to Use COMSOL Multiphysics for Coupled Dual-permeability Hydrological and Slope Stability Modeling. Procedia Earth and Planetary Science, 9: 83-90.

Shao, W., Bogaard, T., Bakker, M., and Berti, M. 2016. The influence of preferential flow on pressure propagation and landslide triggering of the Rocca Pitigliana landslide. Journal of Hydrology, 543B: 360-372.

Shao, W., Bogaard, T. A., Bakker, M., and Greco, R. 2015. Quantification of the influence of preferential flow on slope stability using a numerical modelling approach. Hydrology and earth system Sciences, 19(5): 2197-2212.

Sidle, R. C., and Bogaard, T. A. 2016. Dynamic earth system and ecological controls of rainfall-initiated landslides. Earth-Science Reviews, 159: 275- 291. 
763 Sidle, R. C., Noguchi, S., Tsuboyama, Y., and Laursen, K. 2001. A conceptual model of 764 preferential flow systems in forested hillslopes: evidence of self-organization. Hydrological 765 Processes, 15(10): 1675- 1692.

766

767

768

769

770

771

772

773

774

775

776

777

778

779

780

781

782

783

784

785

786

787

788

789

790

Sidle, R. C., Ochiai, H., Sidle, R.C., and Ochiai, H. 2013. Landslides: Processes, Prediction, and Land Use, pp. 41-119, American Geophysical Union.

Simunek, J., Van Genuchten, M. T., and Sejna, M. 2005. The HYDRUS-1D software package for simulating the one-dimensional movement of water, heat, and multiple solutes in variably-saturated media, pp. 1-240.

Snyder, K. A., Richards, J. H., and Donovan, L. A. 2003. Night-time conductance in $\mathrm{C}_{3}$ and $\mathrm{C}_{4}$ specises: do plants lose water at night? Journal of Experimental Botany, 54(383): 861 865.

Talebi, A., Uijlenhoet, R., and Troch, P. A. 2008. A low-dimensional physically based model of hydrologic control of shallow landsliding on complex hillslopes. Earth Surface Processes and Landforms, 33(13): 1964 - 1976.

Uchida, T. 2004. Clarifying the role of pipe flow on shallow landslide initiation. Hydrological Processes, 18(2): 375- 378 .

Van Asch, T. W. J., Buma, J., and Van Beek, L. P. H. 1999. A view on some hydrological triggering systems in landslides. Geomorphology, 30(1-2), 25-32.

van Dam, J. C., and Feddes, R. A. 2000. Numerical simulation of infiltration, evaporation and shallow groundwater levels with the Richards equation. Journal of Hydrology, 233(1-4): 72 85.

Van Genuchten, M. T. 1980. A closed-form equation for predicting the hydraulic conductivity of unsaturated soils. Soil science society of America journal, 44(5): 892- 898.

Vergani, C., and Graf, F. 2015. Soil permeability, aggregate stability and root growth : a pot experiment from a soil bioengineering perspective. Ecohydrology, doi: 10.1002/eco.1686.

Wang, D., Kang, Y., and Wan, S. 2007. Effect of soil matric potential on tomato yield and water use under drip irrigation condition. Agricultural Water Management, 87(2): 180-186. 
791

792

793

794

795

796

797

798

799

800

801

802

803

804

805

806

807

808

809

810

811

812

813

814

815

816

817

818

819

820

821

822

823

\section{A summary of figure captions}

Figure 1. Schematic diagrams of a test drum and instrumentation ( $\mathrm{Ng}$ et al. 2016b)

Figure 2. (a) Images of the root system for D36, (b) images of the root system for D320, (c) the measured RAI after a 4-month growing period ( $\mathrm{Ng}$ et al. 2016b)

Figure 3. Soil water retention curve of (a) bare soil, (b) single- and (d) dual-permeability model in low planting density soil (D36), and (d) single- and (e) dual-permeability model in high planting density soil (D320)

Figure 4. Comparison of the measurements (hexagram dots) and the simulations of cumulative infiltration and infiltration rate by the single- and dual- permeability models (lines) in low planting density soil D36 (left column) and high planting density soil D320 (right column)

Figure 5. Comparison of the measured and simulated pore water pressure profiles by using the single- and dual- permeability models: (a) D36 and (b) D320 after1 h rainfall, and (c) D36 and (d) D320 at $2 \mathrm{~h}$ rainfall

Figure 6. Simulated vertical profiles of soil water content $(\theta)$ and pore water pressure $(p)$ in D36 and D320 soils by using the single-permeability model during the 2 hours of rainfall

Figure 7. Simulated vertical profiles in D36 soil by the dual-permeability model during the 2 hours of rainfall: soil water content in (a) the matrix domain, (b) the preferential flow domain, and (c) the total domain; pore water pressure in (d) the matrix domain and (e) the preferential domain; and (f) the water exchange rate (positive denotes water exchange from the preferential flow domain to the matrix domain)

Figure 8 . Simulated vertical profiles in D320 soil by the dual-permeability model during the 2 hours of rainfall: soil water content in (a) the matrix domain, (b) the preferential flow domain, and (c) the total domain; pore water pressure in (d) the matrix domain and (e) the preferential domain; and (f) the water exchange rate (positive denotes the water exchange from the preferential flow domain to the matrix domain)

Figure 9. Effects of planting density on factor of safety $\left(\mathrm{F}_{\mathrm{s}}\right)$ before and after the $2 \mathrm{~h}$ rainfall predicted by the single- and dual-permeability models (for $p_{\text {eff }}=p_{f}$ )

Figure 10. Effects of the choice of flow domain in the dual-permeability model on the slope stability 
Table 1. Soil hydraulic parameters for the single-permeability model (Single), and the dual-permeability model (Dual) for the matrix and preferential flow (PF) domains

\begin{tabular}{|c|c|c|c|c|c|c|c|c|c|c|c|}
\hline Model & Soil & $\begin{array}{l}\text { Depth } \\
(\mathrm{m})\end{array}$ & Domain & $\begin{array}{l}w \\
(-)\end{array}$ & $\begin{array}{l}\theta_{\mathrm{r}} \\
(-) \\
\end{array}$ & $\begin{array}{l}\theta_{\mathrm{s}} \\
(-) \\
\end{array}$ & $\begin{array}{c}K_{\mathrm{s}} \\
\text { (m/day) }\end{array}$ & $\begin{array}{c}\alpha \\
\left(\mathrm{m}^{-1}\right) \\
\end{array}$ & $\begin{array}{l}n \\
(-) \\
\end{array}$ & $\begin{array}{c}l \\
(-) \\
\end{array}$ & $\begin{array}{r}a_{w} \\
\left(\mathrm{~m}^{-2}\right) \\
\end{array}$ \\
\hline \multirow{3}{*}{ Single } & Bare & $0-0.45$ & Total domain & - & 0.1 & 0.3 & 0.075 & 5 & 1.25 & 0.5 & - \\
\hline & D36 & $0-0.16$ & Total domain & - & 0.1 & 0.3 & 0.060 & 4 & 1.26 & 0.5 & - \\
\hline & $\mathrm{D} 320$ & $0-0.13$ & Total domain & - & 0.1 & 0.3 & 0.175 & 6 & 1.37 & 0.5 & - \\
\hline \multirow{8}{*}{ Dual } & \multirow{4}{*}{ D36 } & \multirow{2}{*}{$0-0.16$} & Matrix domain & 0.9 & 0.1 & 0.29 & 0.018 & 5 & 1.25 & 0.5 & \multirow{2}{*}{25} \\
\hline & & & PF domain & 0.1 & 0.1 & 0.39 & 4.5 & 6 & 1.50 & 0.5 & \\
\hline & & \multirow{2}{*}{$0.16-0.45$} & Matrix domain & 0.9 & 0.1 & 0.29 & 0.018 & 5 & 1.25 & 0.5 & \multirow{2}{*}{25} \\
\hline & & & PF domain & 0.1 & 0.1 & 0.39 & 0.018 & 5 & 1.25 & 0.5 & \\
\hline & \multirow{4}{*}{ D320 } & \multirow{2}{*}{$0-0.13$} & Matrix domain & 0.8 & 0.1 & 0.27 & 0.075 & 5 & 1.30 & 0.5 & \multirow{2}{*}{15} \\
\hline & & & PF domain & 0.2 & 0.1 & 0.39 & 4.5 & 10 & 1.50 & 0.5 & \\
\hline & & \multirow{2}{*}{$0.13-0.45$} & Matrix domain & 0.8 & 0.1 & 0.27 & 0.075 & 5 & 1.25 & 0.5 & \multirow{2}{*}{15} \\
\hline & & & PF domain & 0.2 & 0.1 & 0.39 & 0.115 & 5 & 1.25 & 0.5 & \\
\hline
\end{tabular}

Note: for the single-permeability model, the hydraulic parameters for the soil below the root zone are specified to be the same as those for the bare soil. 


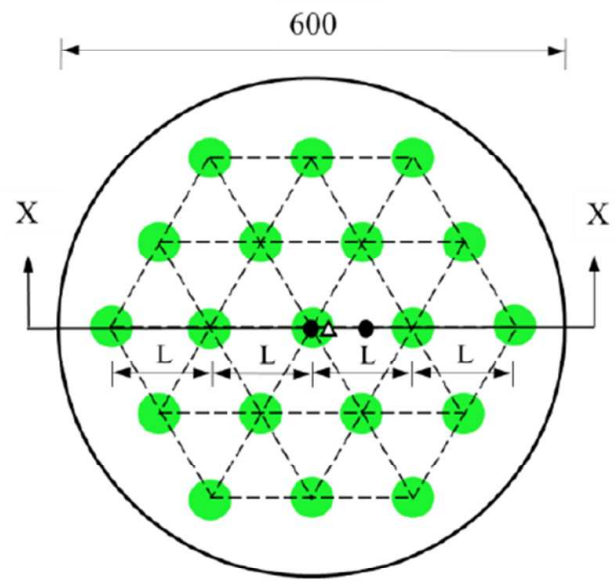

Plan view

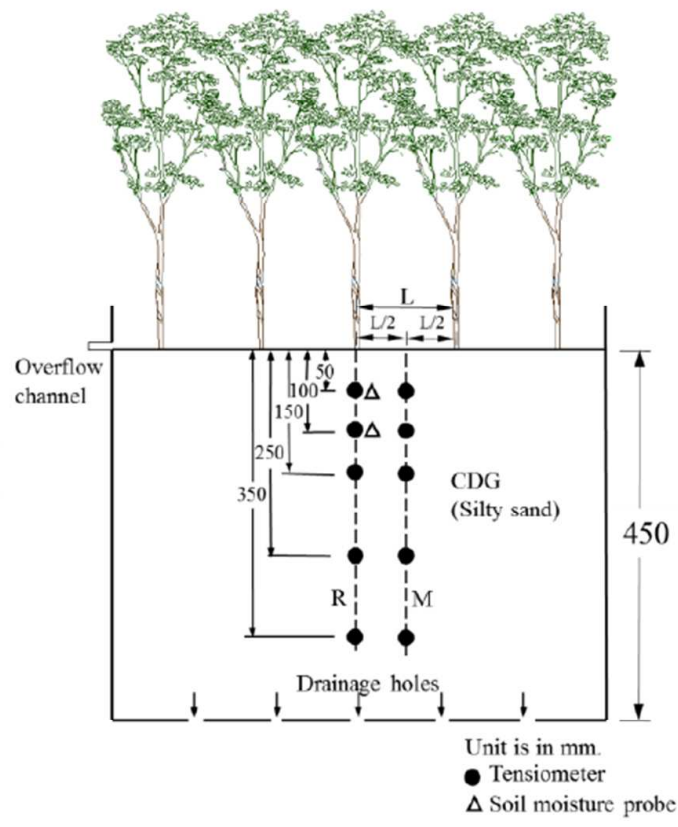

Section X-X

Figure 1. Schematic diagrams of a test drum and instrumentation (Ng et al., 2016b) 
a. Low planting density D36

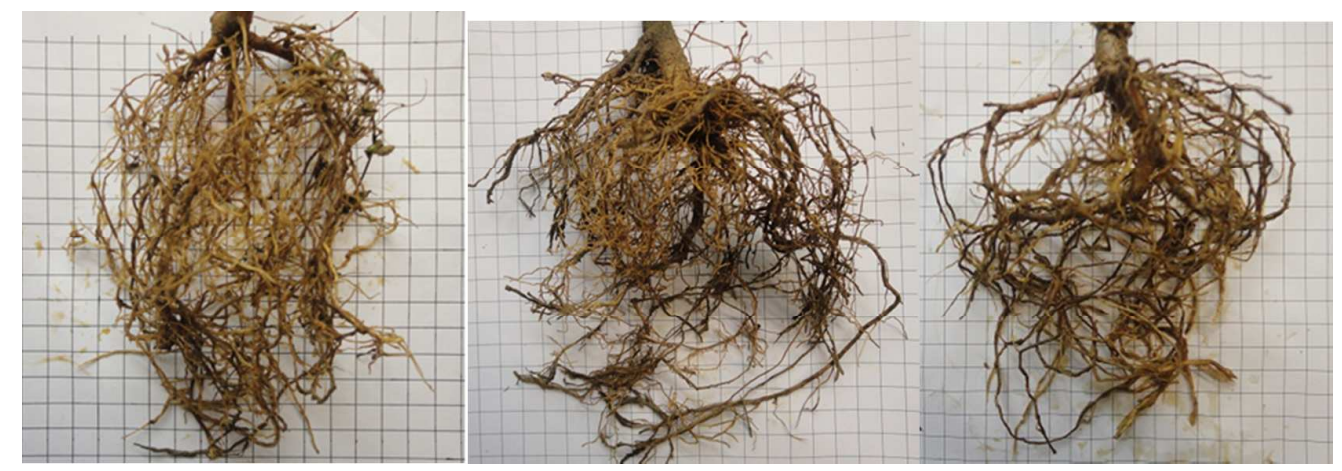

b. High planting density D320

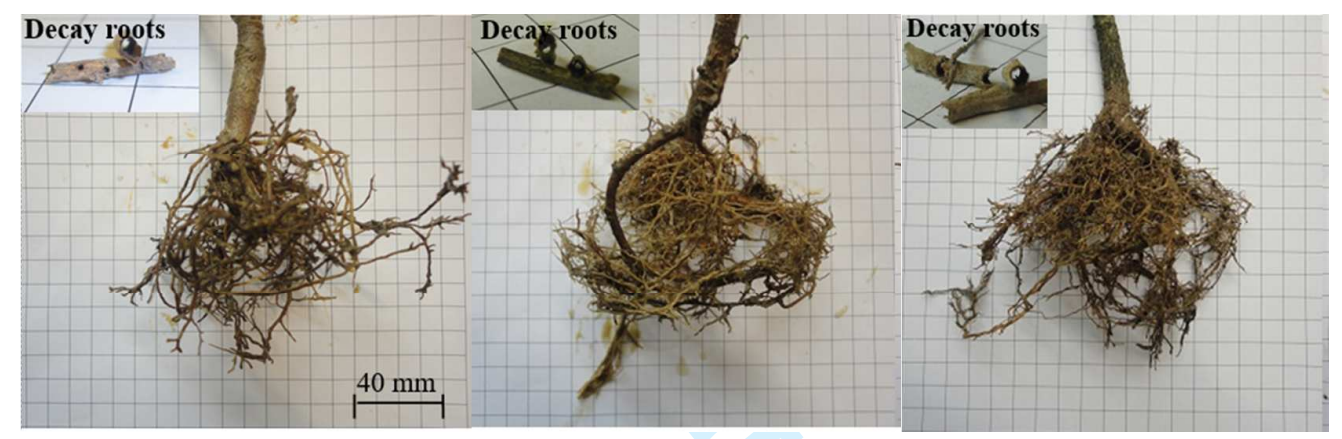

c. Measured RAI

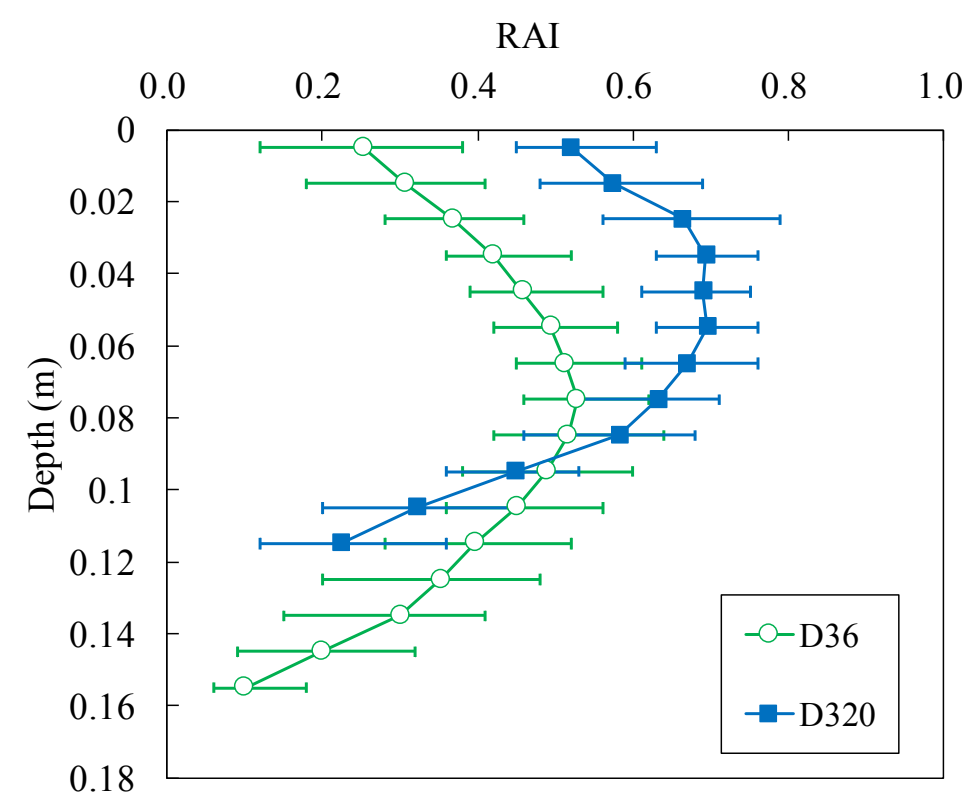

Figure 2. (a) Images of the root system for D36, (b) images of the root system for D320, (c) the measured RAI after a 4-month growing period (Ng et al., 2016b) 

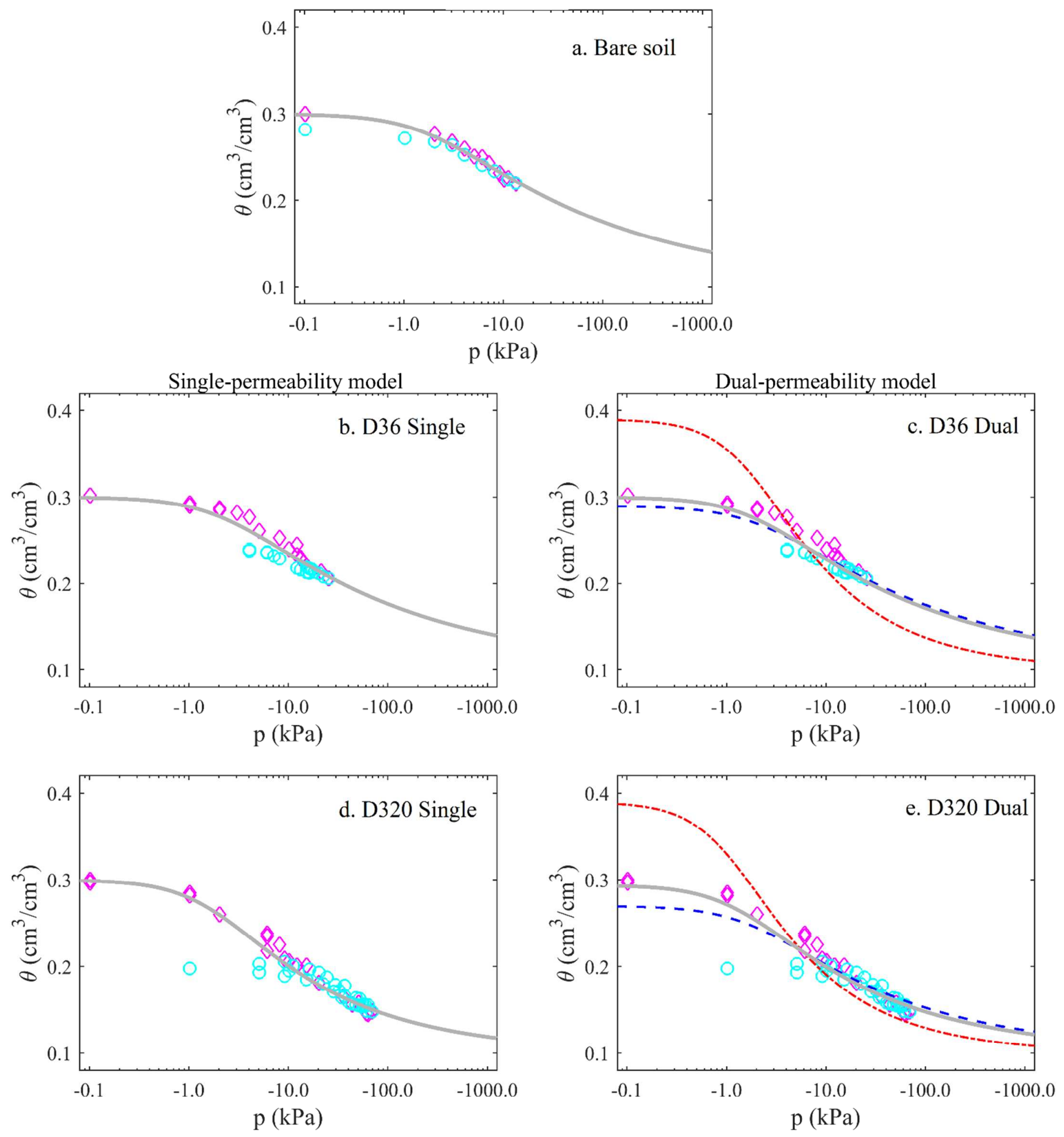

$$
\diamond \quad \text { Measurement (drying) } \bigcirc \quad \text { Measurement (wetting) }-\cdots-\theta_{\mathrm{f}}\left(\mathrm{h}_{\mathrm{f}}\right)---\theta_{\mathrm{m}}\left(\mathrm{h}_{\mathrm{m}}\right) \rightleftharpoons \theta(\mathrm{h})
$$

Figure 3. Soil water retention curve of (a) bare soil, (b) single- and (d) dual-permeability model in low planting density soil (D36), and (d) single- and (e) dual-permeability model in high planting density soil (D320) 

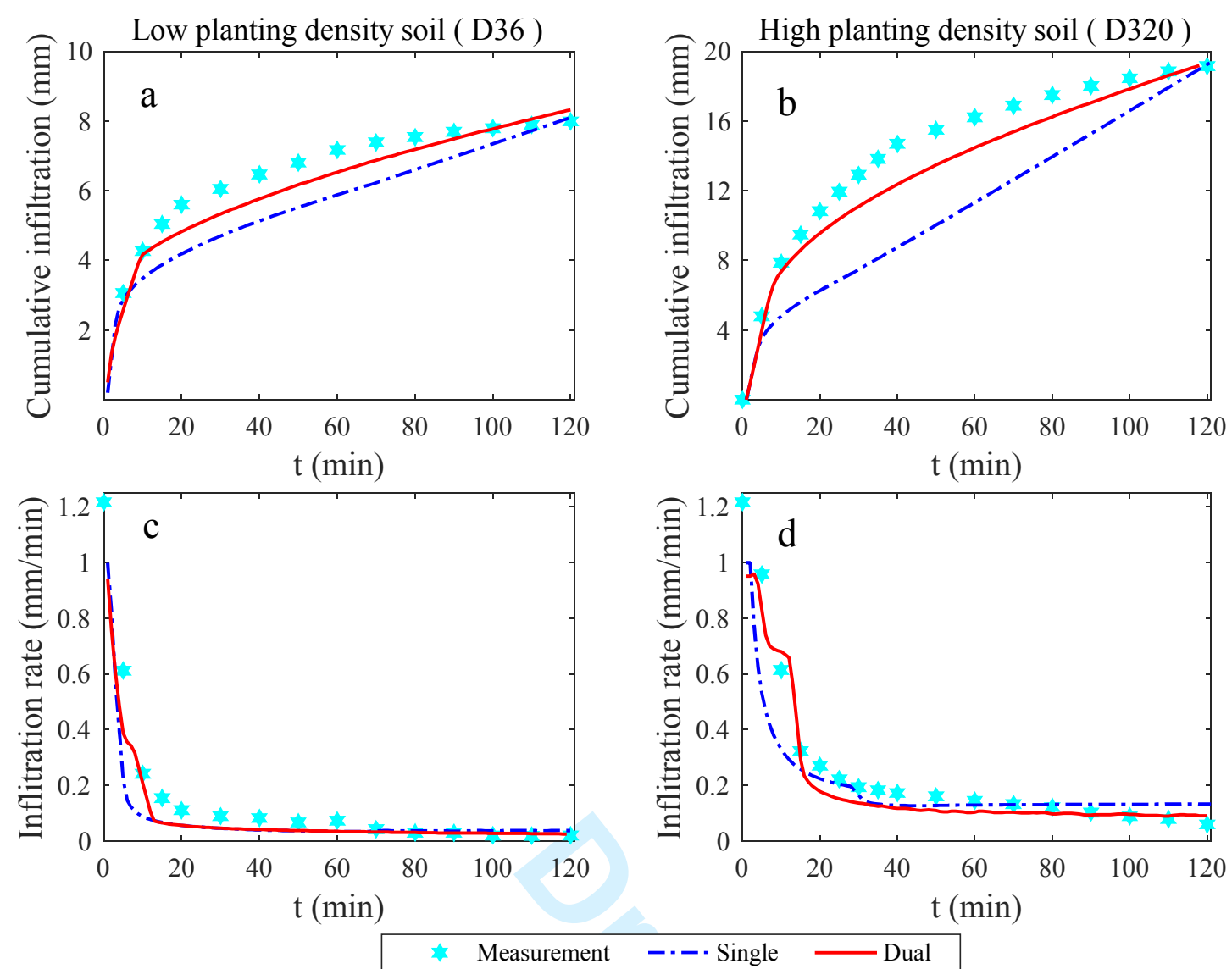

Figure 4. Comparison of the measurements (hexagram dots) and the simulations of cumulative infiltration and infiltration rate by the single- and dual- permeability models (lines) in low planting density soil D36 (left column) and high planting density soil D320 (right column) 

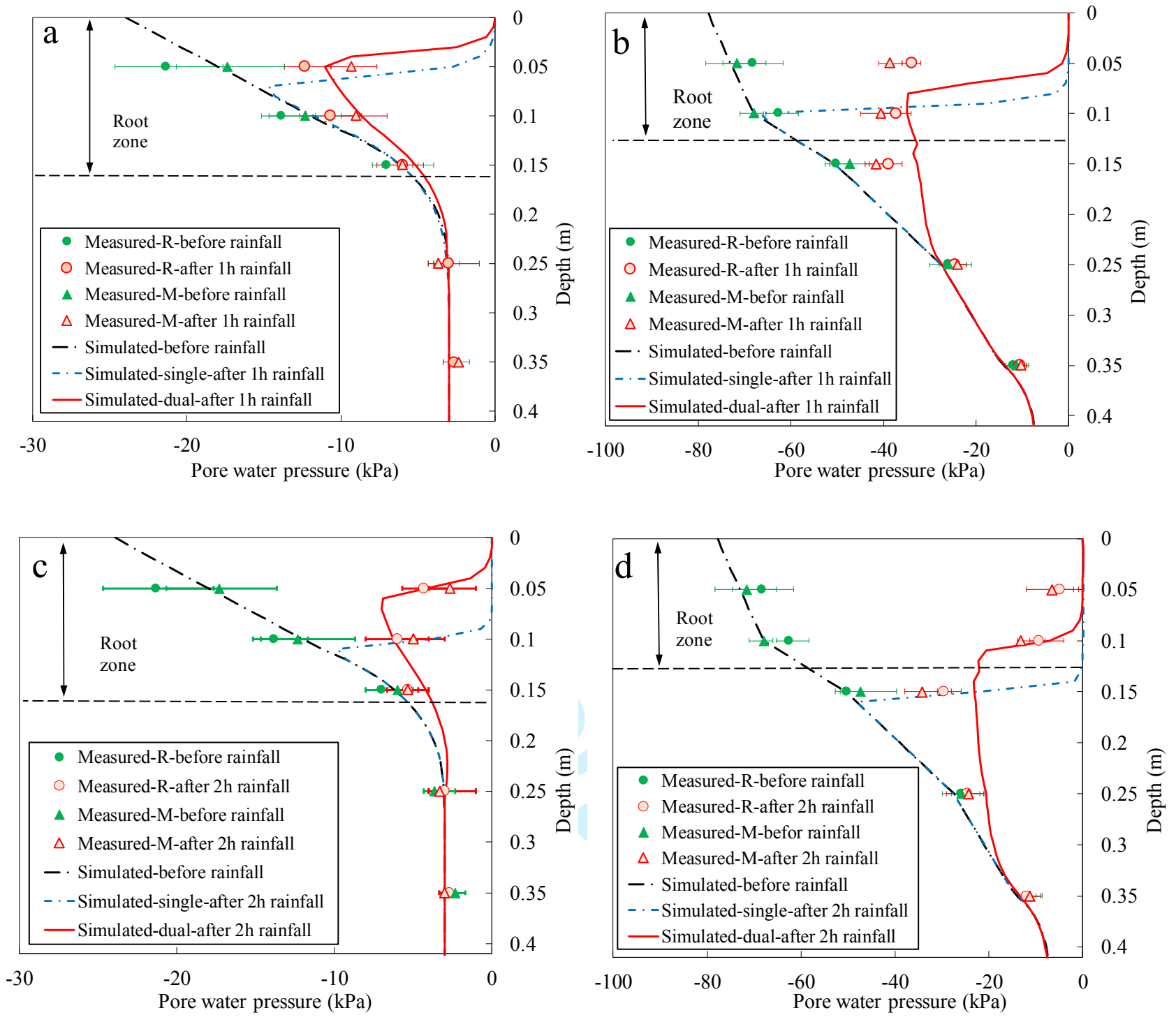

Figure 5. Comparison of the measured and simulated pore water pressure profiles by using the single- and dual- permeability models: (a) D36 and (b) D320 afterl $\mathrm{h}$ rainfall, and (c) D36 and (d) D320 at $2 \mathrm{~h}$ rainfall 

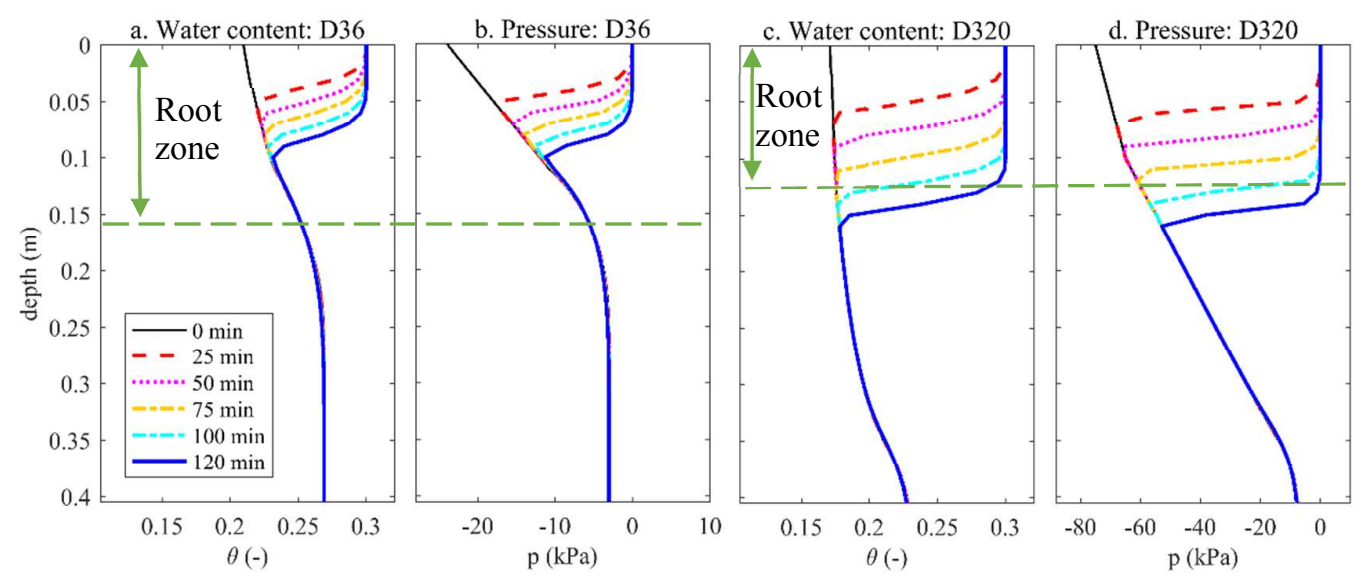

Figure 6. Simulated vertical profiles of soil water content $(\theta)$ and pore water pressure $(p)$ in D36 and D320 soils by using the single-permeability model during the 2 hours of rainfall 

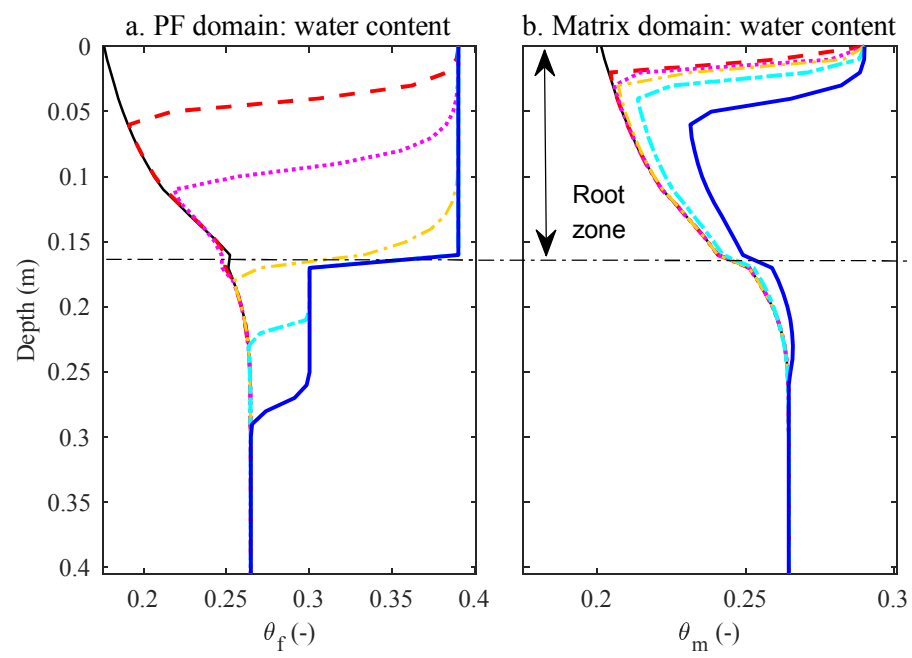

c. Total water content
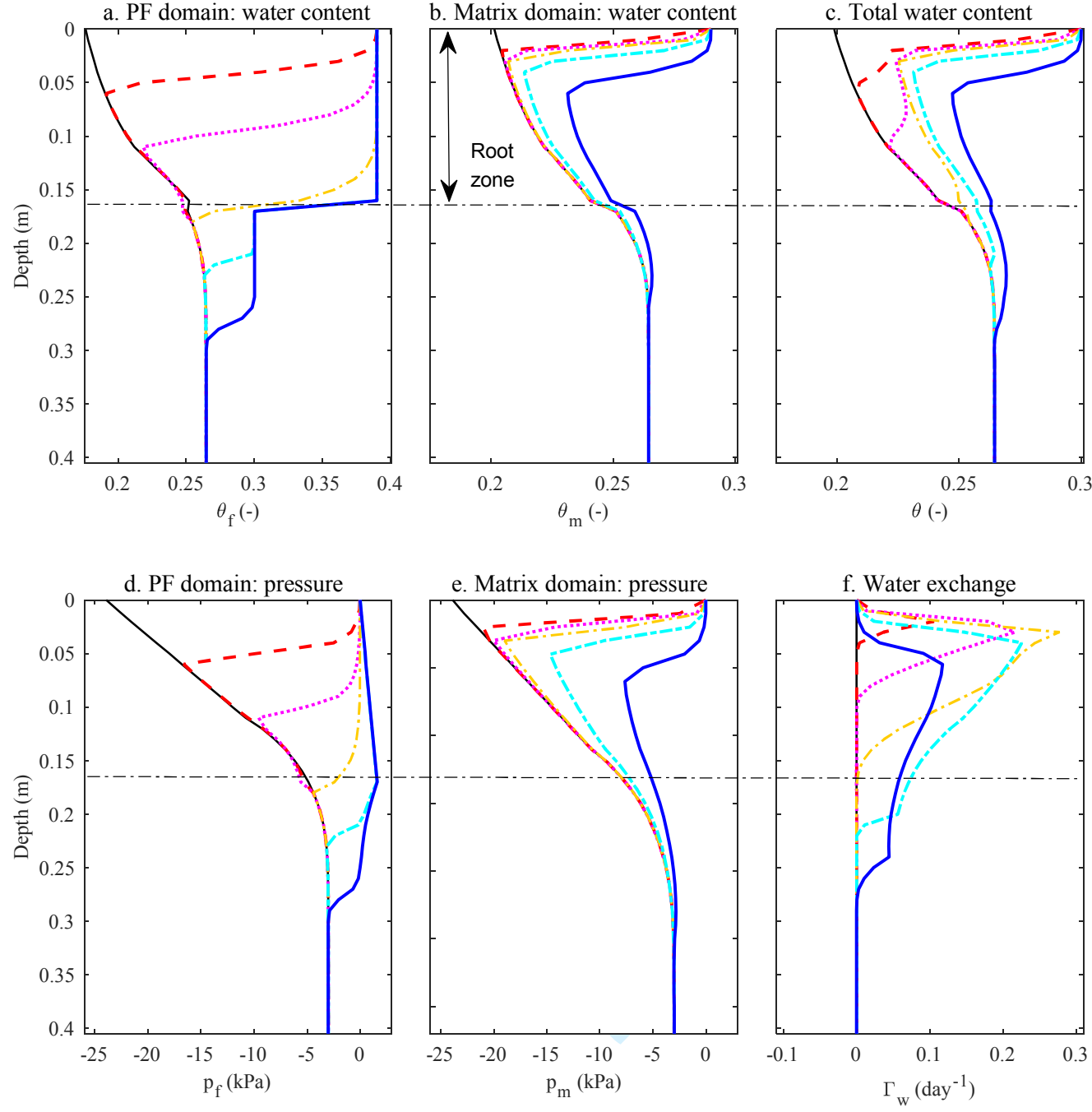

$-0 \min --2 \min \cdots \cdots \cdots \cdot 5 \min -\cdot-\cdot 10 \min -=--30 \min \longrightarrow 120 \min$

Figure 7. Simulated vertical profiles in D36 soil by the dual-permeability model during the 2 hours of rainfall: soil water content in (a) the matrix domain, (b) the preferential flow domain, and (c) the total domain; pore water pressure in (d) the matrix domain and (e) the preferential domain; and (f) the water exchange rate (positive denotes water exchange from the preferential flow domain to the matrix domain) 

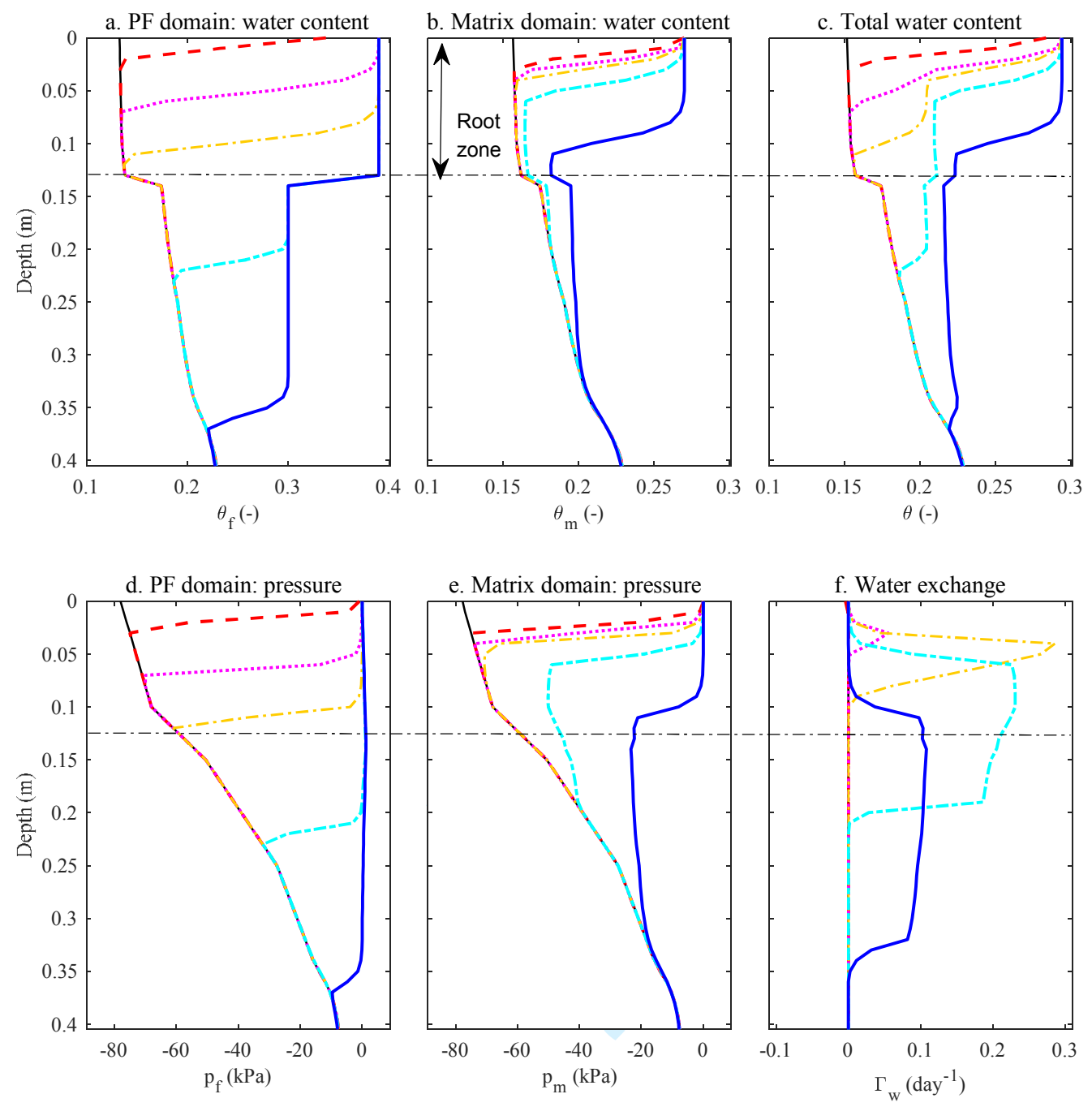

$-0 \min --2 \min \cdots \cdots \cdots \cdot 5 \min -\cdot-\cdot 10 \min ---=30 \min \longrightarrow 120 \min$

Figure 8. Simulated vertical profiles in D320 soil by the dual-permeability model during the 2 hours of rainfall: soil water content in (a) the matrix domain, (b) the preferential flow domain, and (c) the total domain; pore water pressure in (d) the matrix domain and (e) the preferential domain; and (f) the water exchange rate (positive denotes the water exchange from the preferential flow domain to the matrix domain) 


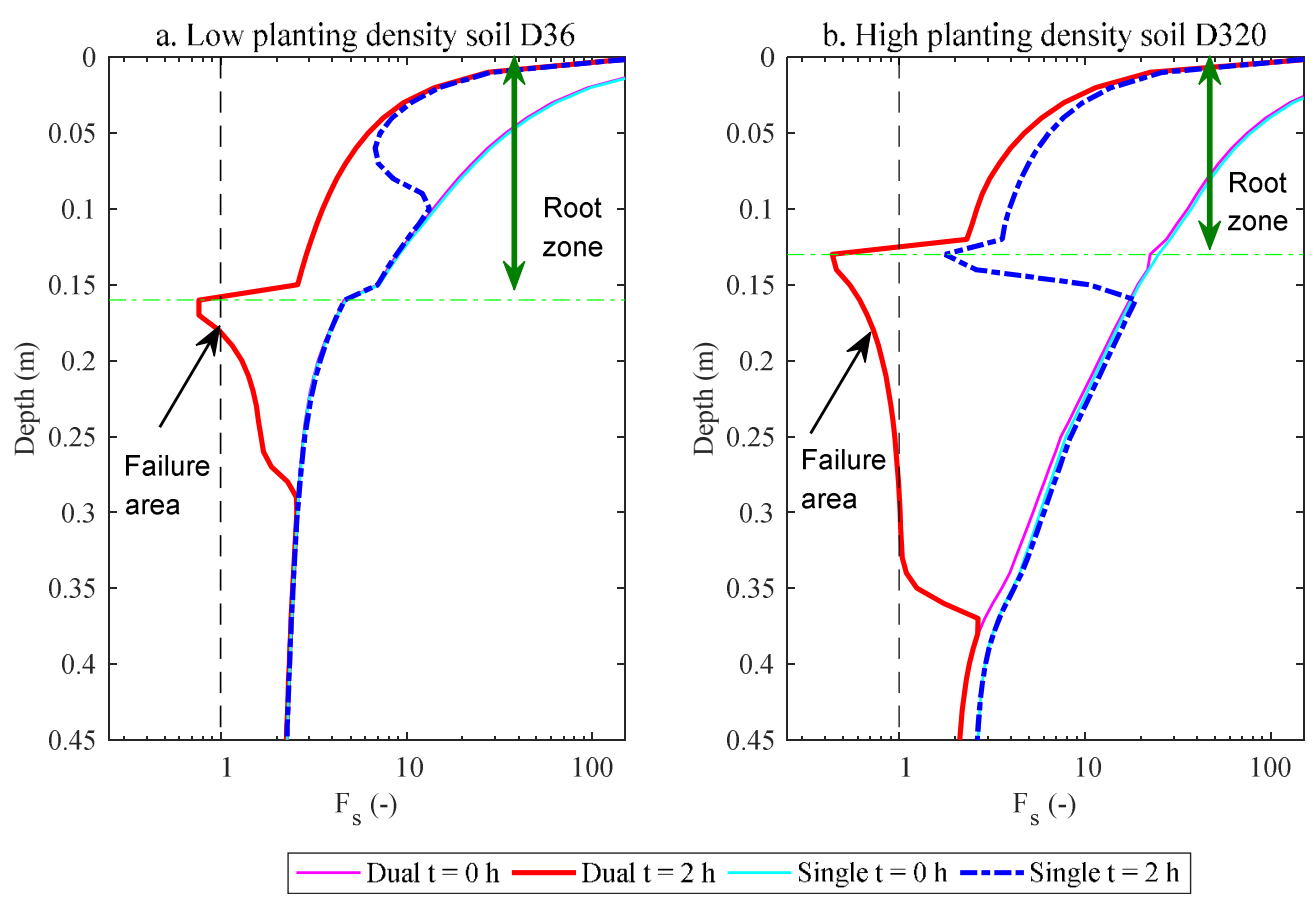

Figure 9. Effects of planting density on factor of safety $\left(\mathrm{F}_{\mathrm{s}}\right)$ before and after the $2 \mathrm{~h}$ rainfall predicted by the single- and dual-permeability models (for $p_{\text {eff }}=p_{f}$ ) 


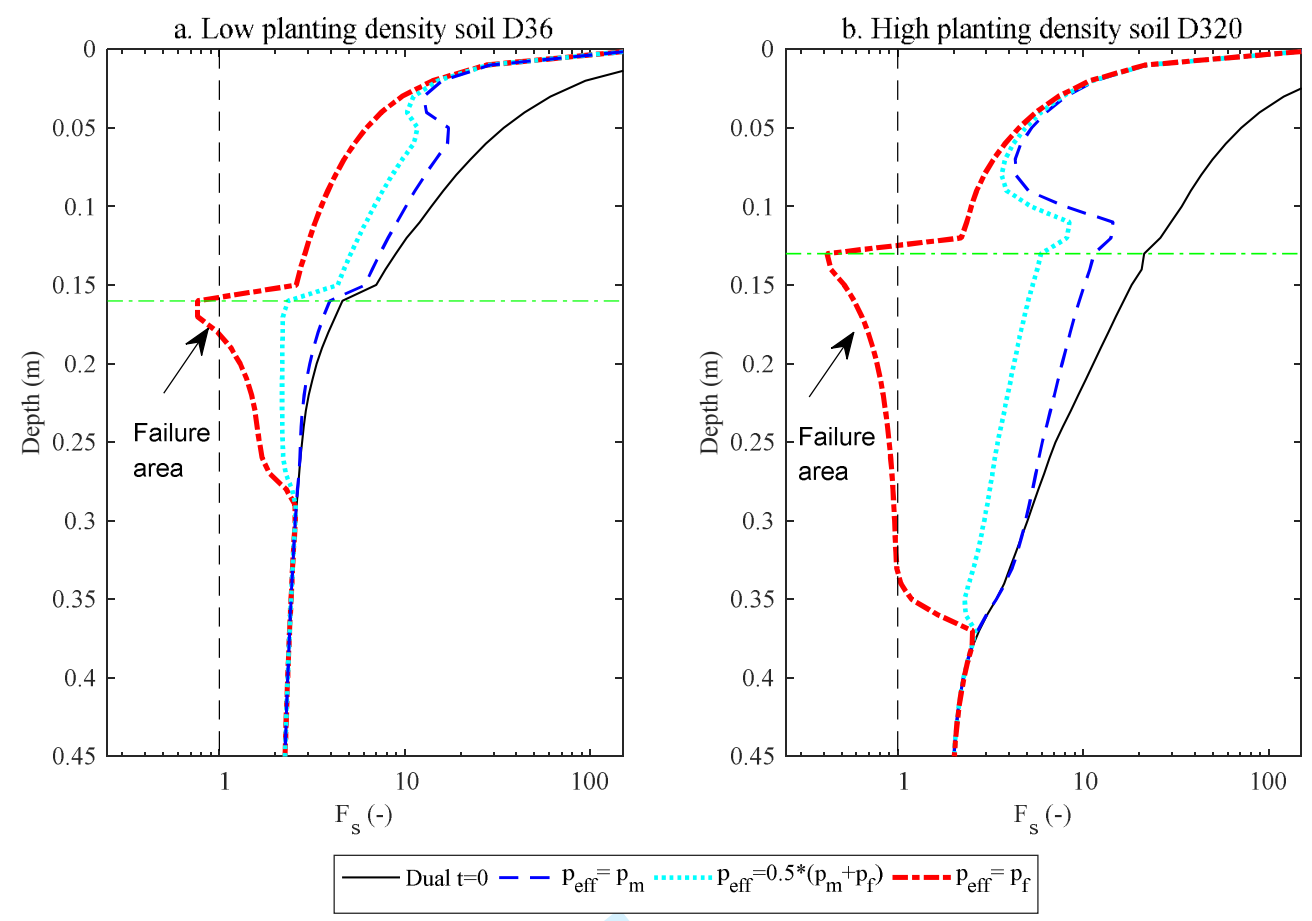

Figure 10. Effects of the choice of flow domain in the dual-permeability model on the slope stability 